\title{
The use of Alizarin modified bentonite for removal of some heavy metals ions from the wet process phosphoric acid
}

\author{
Mohamed A. Awadallah ${ }^{1 *}$, Mohamed N. Rashed ${ }^{1}$, Adila E. Mohamed ${ }^{1}$, Mohamed F. \\ Cheira $^{2}$ \\ ${ }^{1}$ Chemistry department, Faculty of Science, Aswan University, Egypt. \\ ${ }^{2}$ Nuclear Materials Authority, P.O. Box 530 El Maadi, Cairo, Egypt.
}

\begin{abstract}
Wet process phosphoric acid is used in many fields after purification from its impurities. For this purpose, the aim of the present study is the production of the purified WPPA using economic adsorbent that is prepared by impregnation of activated bentonite with Alizarin to improve the adsorption capacity for the metallic impurities $\left(\mathrm{Pb}^{2+}, \mathrm{Ni}^{2+}\right.$, and $\left.\mathrm{Zn}^{2+}\right)$ in wet process phosphoric acid. This adsorbent is characterized by XRD, SEM-EDX, and FT-IR techniques. The adsorption process is studied as a function of influencing parameters such as $\mathrm{H}_{3} \mathrm{PO}_{4}$ concentration, $\mathrm{pH}$, different metallic impurities concentration, AIAB dose, contact time and temperature. The optimum adsorption parameters are applied on the WPPA to gain the purified WPPA. The adsorption-desorption procedures are repeated the number of times up to desorption efficiencies are reduced from $98 \%$ to $82 \%$ for the studied adsorbent after five consecutive cycles, which indicated that the good adsorption stability of the AIAB adsorbent for $\mathrm{Pb}^{2+}, \mathrm{Ni}^{2+}$, and $\mathrm{Zn}^{2+}$ ions.
\end{abstract}

Keywords: Phosphoric acid, activated bentonite, Alizarin, impurities, Removal.

\section{Introduction}

Phosphoric acid has a vital value in the various fields such as agriculture, pharmaceutical products, and industry. Phosphoric acid is used primarily in the manufacture of fertilizers, detergents, and pharmaceuticals (Foods Standards Agency, 2012). In the steel industry, it is used to clean and rust-proof the product. It is also used as a flavoring agent in carbonated beverages, beer, jams, jellies, and cheeses. It is also used in dental cement, in the preparation of albumin derivatives, and in the sugar and textile industries (Slack, 1968).

Manufacture of phosphoric acid essentially depends on the grade of phosphate rock according to the high grade of $\mathrm{P}_{2} \mathrm{O}_{5}$ and low concentrations of impurities such as F-, $\mathrm{SiO}_{2}$, $\mathrm{Fe}_{2} \mathrm{O}_{3}, \mathrm{Al}_{2} \mathrm{O}_{3}, \mathrm{MgO}, \mathrm{CO}_{3}{ }^{2-}$, organic matter, and chloride ions. These impurities are caused problems in the manufacturing process and produced highly impure phosphoric acid which is required much purification processes. The wet process phosphoric acid was generally produced by the treatment of phosphate rock with sulfuric acid in the temperature range of 70-80 ${ }^{\circ} \mathrm{C}$ (Abdel Aal and Amer, 1991; Becker, 1989; Elleuch et al., 2006). The product acid might be purified to obtain different grades. Based on purity, there were different grades of phosphoric acid available on the market today. These were included food grade, industrial grade, and fertilizer grade. Commercial markets for phosphoric acid were broadly divided into two categories: agricultural and industrial. The proper grade of phosphoric acid was used for their particular applications (Lokshin et al., 2002). 
* Corresponding Author: mf.farid2008@yahoo.com

Separation of organic and inorganic impurities from wet process phosphoric acid could be applied by several techniques which were performed to develop for the effective separation of heavy and harmful metal ions from wet process phosphoric acid (Monser et al., 1999). The choice of an economically suitable technique depends upon many parameters such as the concentration of wet process phosphoric acid, the amount and the concentration of the co-dissolved impurities. These techniques are precipitation (Abdennebi et al., 2017), floatation (Haraldsen, 1991), membrane extraction (Al-Harahsheh et al., 2017; Machorro et al., 2013), crystallization ((Aaltonen et al., 2004; Chen et al., 2012), ion exchange (Marcus et al., 2004; Cheira, 2015), liquid-liquid extraction (Singh et al., 2009; Chen et al., 2016; Assuncao et al., 2017; Li et al., 2017), and solid phase extraction (Awwad et al., 2013 ).

The montmorillonite is used currently both as a group name for all clay minerals with an expanding lattice, except vermiculite, and also as specific mineral name. The chemical formula of bentonite and Montmorillonite are $\left(\mathrm{Al}_{2} \mathrm{O}_{3} \cdot 4 \mathrm{SiO}_{2} \cdot \mathrm{H}_{2} \mathrm{O}\right)$ and $\left(\mathrm{Na}_{0.2} \mathrm{Ca}_{0.1} \mathrm{Al}_{2} \mathrm{Si}_{4} \mathrm{O}_{10}(\mathrm{OH})_{2}\left(\mathrm{H}_{2} \mathrm{O}\right)_{10}\right)$ respectively (Grim, 1968). Bentonite is characterized by several features, such as swelling ability as a result of water adsorption and de-colorization, which led to its utilization in many fields. The crystalline structure of clay is known as 2:1 type aluminosilicate, presenting an octahedral alumina between two tetrahedral silica layers (Vimonses et al., 2009).

Continuous efforts have been made to develop new adsorptions for the separation of hazards and harmful impurities from WPPA. Kaolin modified by calcination followed by acid activation and it was used for the adsorption of uranium ions from solutions (Wang et al. 2010). The prepared silica obtained from natural rice straw was used as the adsorbent for the removal of metal impurities (especially iron) content from WPPA (El-Zahhar et al., 2005). The removal of copper from the phosphoric acid was studied by adsorption on Tunisian bentonite (Abdennebi et al., 2013). Also, the removal of cadmium from the phosphoric acid solution carried out with solvent-impregnated resin. Cyanex 302 (bis [2, 4, 4-trimethyl pentyl] mono thiophosphinic acid) was used as an extractant for the preparation of solventimpregnated resin (Kabay et al., 2002), as well as the removal of heavy ions from phosphoric acid was applied using triphenylphosphine sulfide (TPPS) in (chloroform) solution impregnated onto charcoal by dry method technique (El-Sofany et al., 2009).

Recently, the natural and activated zeolite and bentonite used for the removal of $\mathrm{Fe}^{2+}$, $\mathrm{Cu}^{2+}, \mathrm{Al}^{3+}$ and $\mathrm{Pb}^{2+}$ ions from phosphoric acid (Sultanbayeva et al., 2013). The activated bentonite is used for organic matter removal from the Tunisian industrial phosphoric acid (Khoualdia et al., 2017). Cheira et al., (2014) studied the potentiality of applying white sand for the purification of wet process phosphoric acid through the adsorption of metallic impurities $\left(\mathrm{U}^{6+}, \mathrm{Zn}^{2+}\right.$, and $\left.\mathrm{Cd}^{2+}\right)$.

Moreover, the sorption ability of the chitosan-modified natural zeolite for $\mathrm{Pb}^{2+}, \mathrm{Cd}^{2+}$, and $\mathrm{Cu}^{2+}$ cations studied from concentrated phosphoric acid (Kussainova et al., 2015). The Amberlite XAD-7 impregnated with Cyanex 301, was selected among several supports and organophosphorus extractants for its high affinity for cadmium in phosphoric acid solution (Reyes et al., 2001). Furthermore, The phosphonate compound amino trimethylene phosphonic acid (ATMP) was impregnated on Amberlite XAD-4 resin and studied for the adsorption of ferric ions from the phosphoric acid solution ( Saleh and El-Zahhar, 2015). Besides that, the uranium sorption from commercial phosphoric acid was applied on kaolinite and metakaolinite (Taha et al., 2018). 
The main objective of the present work are the removal of $\mathrm{Pb}^{2+}, \mathrm{Ni}^{2+}$, and $\mathrm{Zn}^{2+}$ ions from the wet process phosphoric acid. To acquire the adsorption optimum conditions, these parameters which are the acid concentration, the amount of adsorbent, contact time and temperature are applied on the diluted acid and WPPA.

\section{Materials and methods}

\subsection{Characteristics of natural bentonite}

Egypt is one of the countries in the world which recorded a huge potential in mining clay. Bentonite consists essentially of clay minerals of the smectite group; they have a wide range of industrial uses. A particular feature of this group of minerals is the substitution of $\mathrm{Si}^{4+}$ and $\mathrm{Al}^{3+}$ in the crystal structure by lower valency cations (Odom, 1984). The Egyptian bentonite is a grey color and lighter colored after drying.

Natural bentonite (B) used in this study is obtained from El Fayoum area by International Co. for Mining and Investments - ICMI, Egypt. The bentonite is sieved to give different particle size fractions using ASTM standard sieves analysis of fine and coarse

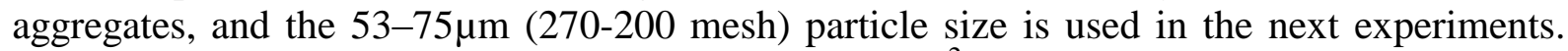
The BET specific surface area was measured to be $28 \mathrm{~m}^{2} / \mathrm{g}$ from $\mathrm{N}_{2}$ adsorption isotherm with a sorptiometer (Quantachrome Co., NOVA 2000).

The chemical composition of bentonite is given in Table (1) which is presented the major chemical constituents of natural bentonite and activated bentonite, respectively. The high concentration of $\mathrm{SiO}_{2}$ and $\mathrm{Al}_{2} \mathrm{O}_{3}$ confirms that bentonite is an alumino-silicate material whereas high-silica montmorillonite is enriched with potassium, sodium, and magnesium.

Structurally, bentonite clay is made up of two basic building blocks, i.e. the aluminum octahedral sheets and silica tetrahedral sheets (Figure 1). A single unit cell consists of one aluminum octahedral sheet sandwiched between two tetrahedral silica sheets. These silicate layers have a slight negative charge that is compensated by exchangeable cations in the intermediate layers (Alexandre et al., 2009).

Table 1: Chemical analysis of natural and activated bentonite

\begin{tabular}{|c|c|c|}
\hline Chemical species & $\begin{array}{l}\text { Natural bentonite } \\
(\mathbf{\%})\end{array}$ & $\begin{array}{c}\text { Activated bentonite } \\
(\boldsymbol{\%})\end{array}$ \\
\hline $\mathbf{S i O}_{\mathbf{2}}$ & 58.18 & 61.45 \\
$\mathbf{A l}_{\mathbf{2}} \mathbf{O}_{3}$ & 17.26 & 17.65 \\
$\mathbf{T i O}_{\mathbf{2}}$ & 0.11 & 0.11 \\
$\mathbf{F e}_{\mathbf{2}} \mathbf{O}_{\mathbf{3}}$ & 4.24 & 4.21 \\
$\mathbf{M n O}$ & 0.07 & 0.07 \\
$\mathbf{C a O}$ & 3.74 & 3.41 \\
$\mathbf{M g O}$ & 2.14 & 1.11 \\
$\mathbf{K}_{\mathbf{2}} \mathbf{O}$ & 1.96 & 0.11 \\
$\mathbf{N a}_{2} \mathbf{O}$ & 2.85 & 0.22 \\
$\mathbf{P}_{\mathbf{2}} \mathbf{O}_{\mathbf{5}}$ & 0.19 & 0.17 \\
$\mathbf{L . O . I}$ & 9.15 & 9.95 \\
Total & 99.89 & 99.46 \\
\hline
\end{tabular}

L.O.I*: Total Loss of Ignition at $1000^{\circ} \mathrm{C}$. 
Figure 1: Suggested structure of Egyptian natural bentonite

\subsection{Preparation of activated bentonite}

The term activation refers to chemical and physical treatments employed to enhance the adsorption capacities of clays (Christidis et al., 1997). The natural bentonite is grinding to appropriate fine size sizes ( $200 \mathrm{mesh})$, then it is dried in the oven at $105^{\circ} \mathrm{C}$. The dried sample (100 g) is mixed and stirred with $1 \mathrm{M} \mathrm{H}_{2} \mathrm{SO}_{4}(300 \mathrm{ml})$ using $300 \mathrm{rpm}$ stirring speed by electrical motor for $2 \mathrm{~h}$ contact time at room temperature. The reaction is performed in a glass flask equipped with a reflux condenser in order to avoid evaporation of the solvent during the experiment. After acid activation, the slurry is filtered, and the filtrate is carefully washed with deionized water until it is free from sulfate ions (tested by $\mathrm{BaCl}_{2}$ solution) and the $\mathrm{pH}$ of the leached solution is ranged from 6 to 7 . The acid-activated sample is initially dried at room temperature, and then at $105{ }^{\circ} \mathrm{C}$ for $3 \mathrm{~h}$.

\subsection{Alizarin impregnated activated bentonite}

The dry method is used for the modified process. The impregnation experiment are performed at the suspended $1.0 \mathrm{~g}$ of activated bentonite in $10 \mathrm{ml}$ of deionized water, then mix well by $0.5 \mathrm{~g}$ Alizarin (99\%, Merck, Germany) which is dissolved in 25 ethyl alcohol (99\%, BDH Chem., England) with stirring under fixed conditions for 60 min contact time at room temperature until complete homogenization followed by leaving the slurry till the solution is evaporated. The modified activated bentonite is then dried at $60{ }^{\circ} \mathrm{C}$ till complete dryness and a powder form of Alizarin impregnated activated bentonite (AIAB) is obtained.

\subsection{Chemical analysis of crude phosphoric acid}

The crude phosphoric acid is gained from Abu Zaabal for Fertilizers and Chemicals Company, It is a green color. The crude phosphoric acid is analyzed to determine their constituents. Where their oxides $\mathrm{SiO}_{2}, \mathrm{Al}_{2} \mathrm{O}_{3}$, and $\mathrm{P}_{2} \mathrm{O}_{5}$ are analyzed using spectrophotometric techniques (Table 2). The content of $\mathrm{Na}$ and $\mathrm{K}$ are determined by the flame photometric technique. The ferric oxide $\left(\mathrm{Fe}_{2} \mathrm{O}_{3}\right)$ is determined by titration with EDTA using sulphosalicylic acid as the indicator. $\mathrm{MgO}$ and $\mathrm{CaO}$ are determined by titration with EDTA using Eriochrome black $\mathrm{T}$ as an indicator from which the amount of calcium is subtracted after being determined using Muruxide as an indicator (Shapiro and Brannock, 1962). Trace elements are also determined using AAS and ICP-OES. 
Table 2: Analysis of the interested constituents of Abu Zaabal crude phosphoric acid

\begin{tabular}{|l|c|l|c|}
\hline $\begin{array}{l}\text { Constituent } \\
\text { s }\end{array}$ & Conc (\%) & $\begin{array}{l}\text { Constituent } \\
\text { s }\end{array}$ & Conc (mg/L) \\
\hline $\mathrm{P}_{2} \mathrm{O}_{5}$ & 44 & $\mathrm{U}^{6+}$ & 54 \\
$\mathrm{CaO}$ & 0.7 & $\mathrm{~Pb}^{2+}$ & 45 \\
$\mathrm{~F}^{-}$ & 0.8 & $\mathrm{Ni}^{2+}$ & 63 \\
$\mathrm{SiO}_{2}$ & 0.5 & $\mathrm{Cd}^{2+}$ & 18 \\
$\mathrm{Na}_{2} \mathrm{O}$ & 0.3 & $\mathrm{Zn}^{2+}$ & 282 \\
$\mathrm{~K}_{2} \mathrm{O}$ & 0.09 & $\mathrm{Cu}^{2+}$ & 43 \\
$\mathrm{MgO}^{2+}$ & $\mathrm{Mn}^{2+}$ & 680 \\
$\mathrm{Fe}_{2} \mathrm{O}_{3}$ & 0.5 & $\mathrm{As}^{5+}$ & 10 \\
$\mathrm{Cl}^{-}$ & 2.4 & $\mathrm{Cr}^{3+}$ & 210 \\
$\mathrm{Al}_{2} \mathrm{O}_{3}$ & 2.7 & $\mathrm{Co}^{3+}$ & 43 \\
$\mathrm{SO}_{4}{ }^{2-}$ & 0.6 & $\mathrm{Ba}^{2+}$ & 1.5 \\
& 1.8 & $\mathrm{Th}^{4+}$ & 0.5 \\
& & $\mathrm{Sr}^{2+}$ & 59 \\
& & $\mathrm{RE}^{3+}$ & 255 \\
\hline
\end{tabular}

\subsection{Control analysis}

The concentration of the studying trace elements in all the working stream phosphoric acid has been determined through atomic absorption spectroscopy for $\mathrm{Pb}^{2+}, \mathrm{Ni}^{2+}$, and $\mathrm{Zn}^{2}$ while the inductively coupled plasma optical emission spectrometry (ICP-OES) has been used for the other trace elements.

\subsection{Clarification of Abu Zaabal WPPA}

A sufficient volume of the Abu Zaabal crude phosphoric acid product has been kindly diluted to simulate the wet process phosphoric acid. From the analysis process, it is shown that $\mathrm{P}_{2} \mathrm{O}_{5}$ attain up to $44.0 \%$. Therefore, it is found convenient to dilute it down to $29 \% \mathrm{P}_{2} \mathrm{O}_{5}$ ( $5 \mathrm{M} \mathrm{H}_{3} \mathrm{PO}_{4}$ ) to signify approximately the composition of the WPPA.

Prior to the purification of wet process phosphoric acid with the studied solvents modified bentonite is passed through the two filter columns. The WPPA is subjected to a pretreatment procedure to obtain the clarified green acid by its filtration through a sand filter column for removal of suspended solids and humic matter that might cause physical problems in the extraction system. This is then followed by treatment with activated carbon filter column for the removal of soluble organic matter (Scheme 1A). The outlet acid solution is collected and introduced for the impurities removal through the adsorption processes.

\subsubsection{Adsorption studies}

Several series of batch adsorption experiments of the study metal ions $\left(\mathrm{Pb}^{2+}\right.$, $\mathrm{Ni}^{2+}$, and $\mathrm{Zn}^{2+}$ ) from phosphoric acid are individually performed using the Alizarin impregnated activated bentonite (AIAB). To optimize the different parameters such as acid concentration, dose amount, contact time as well as the temperature. All these experiments are achieved in duplicate tests to establish the accuracy of the procedure. To realize these objectives, a known volume of the working dilute phosphoric acid $(50 \mathrm{ml})$ is mechanically shaker at a rate $150 \mathrm{rpm}$ with a known weight of the adsorbent in a $100 \mathrm{ml}$ conical flask. 
From each adsorption experiment a number of individual metal ions adsorbed on the AIAB adsorbent $\left(\mathrm{q}_{\mathrm{e}}, \mathrm{mg} / \mathrm{g}\right)$, adsorption efficiency (E, \%), and distribution coefficient $\left(\mathrm{K}_{\mathrm{d}}\right)$ are calculated from the following equations (Cheira, 2015):

$$
\begin{aligned}
& \mathrm{q}_{\mathrm{e}}=\left(\mathrm{C}_{\mathrm{o}}-\mathrm{C}_{\mathrm{e}}\right) \times \frac{\mathrm{V}}{\mathrm{m}} \\
& \mathrm{E}(\%)=\frac{\mathrm{C}_{\mathrm{o}}-\mathrm{C}_{\mathrm{e}}}{\mathrm{C}_{\mathrm{o}}} \times 100 \\
& \mathrm{~K}_{\mathrm{d}}=\frac{\left(\mathrm{C}_{\mathrm{o}}-\mathrm{C}_{\mathrm{e}}\right)}{\mathrm{C}_{\mathrm{e}}} \times \frac{\mathrm{V}}{\mathrm{m}}
\end{aligned}
$$

where $\mathrm{C}_{\mathrm{o}}$ and $\mathrm{C}_{\mathrm{e}}$ are the initial and equilibrium metal ions concentrations $(\mathrm{mg} / \mathrm{L})$, respectively, and $\mathrm{V}$ is the volume of the acid solution (L) and $\mathrm{m}$ is the dry adsorbent weight (g).

\section{Results and Discussion}

\subsection{Adsorbent description}

\subsubsection{Mineralogical studies}

Mineralogical analysis for natural bentonite and activated bentonite as well as Alizarin impregnated bentonite showed that they are essentially montmorillonite as expected (Bihannic et al., 2001).

Natural bentonite seems in the form of dense aggregates cluster, its surface is characterized by the existences of very fine pieces that may be related to the associated mineral impurities. From the obtained data in Figure (2), it is clear that the natural bentonite sample composed mainly of Na-montmorillonite with little amounts of kaolinite, quartz, and calcite. The XRD spectrum of the activated bentonite data in Figure (3) shows the peaks of montmorillonite $\left(2 \theta=6.99, \mathrm{~d}_{(001)}=12.55 \AA\right) ;\left(2 \theta=19.8^{\circ} \mathrm{d}=4.45\right) ;\left(2 \theta=27.75^{\circ} \mathrm{d}=3.32\right)$.

The data in Figures (4-5) show the XRD patterns of the Alizarin impregnated bentonite and metal ions impurities loaded with AIAB. A displacement of the angle $2 \theta$ from $6.99^{\circ}$ to $5.4^{\circ}$ with an obvious increase in the $\mathrm{d}_{001}$ value from $12.55 \AA$ for the natural bentonite to $19.33 \AA$ for the Alizarin impregnated bentonite respectively, confirming the intercalation of the organic ions in the interlayer space and by the same the expansion of the layers of the montmorillonite. On the basis of XRD data' natural bentonite and different forms of bentonite are fairly similar between $5^{\circ}$ and $82^{\circ}$, which signifies that the structure of bentonite was not, destroyed during treatment and impregnation processes.

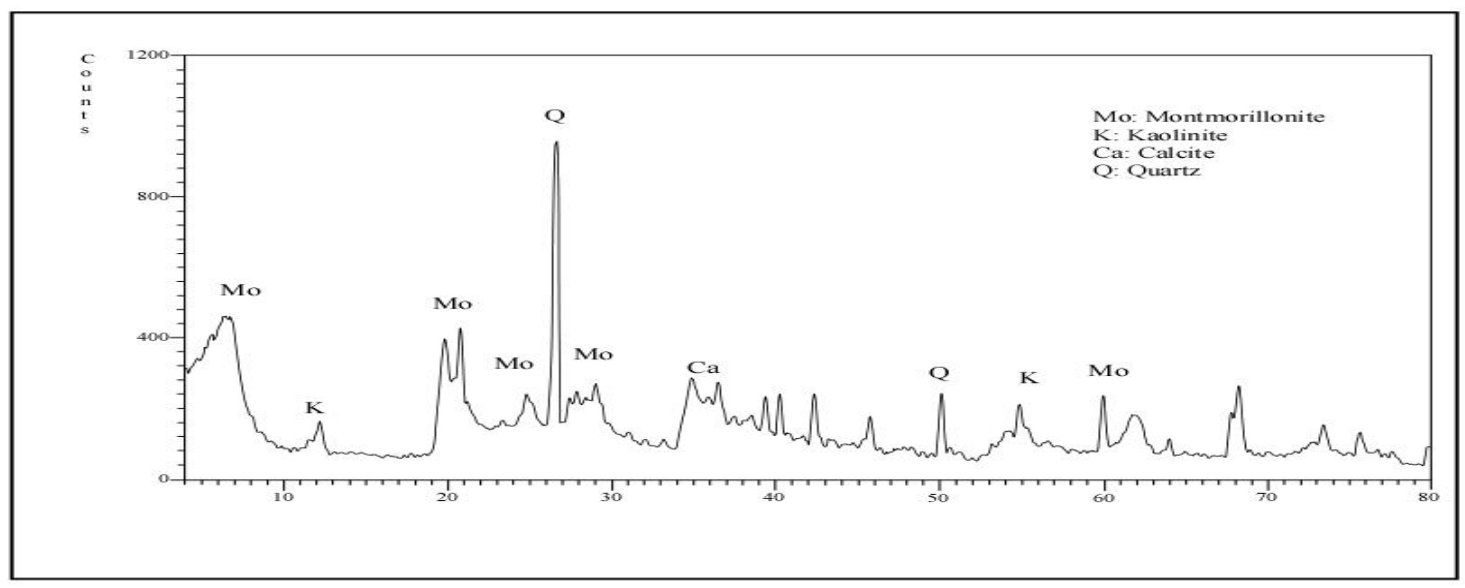

Figure 2: The XRD spectrum of natural bentonite 


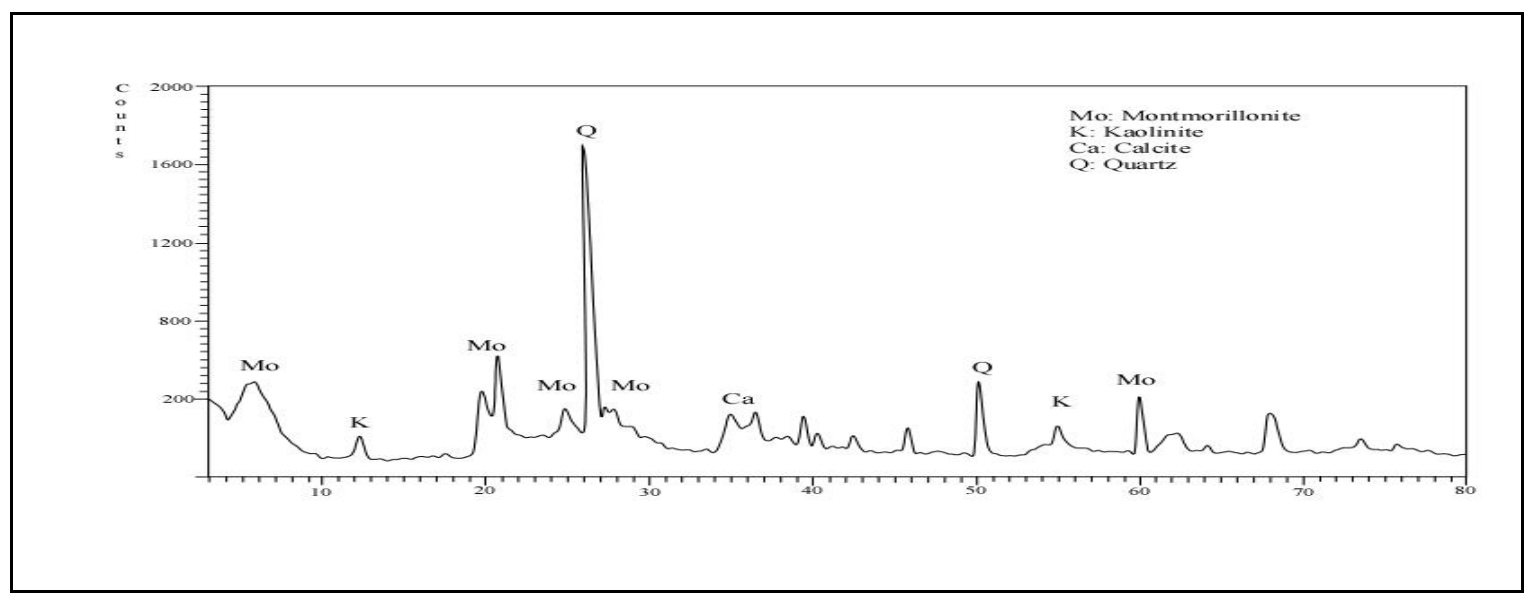

Figure 3: The XRD spectrum of activated bentonite

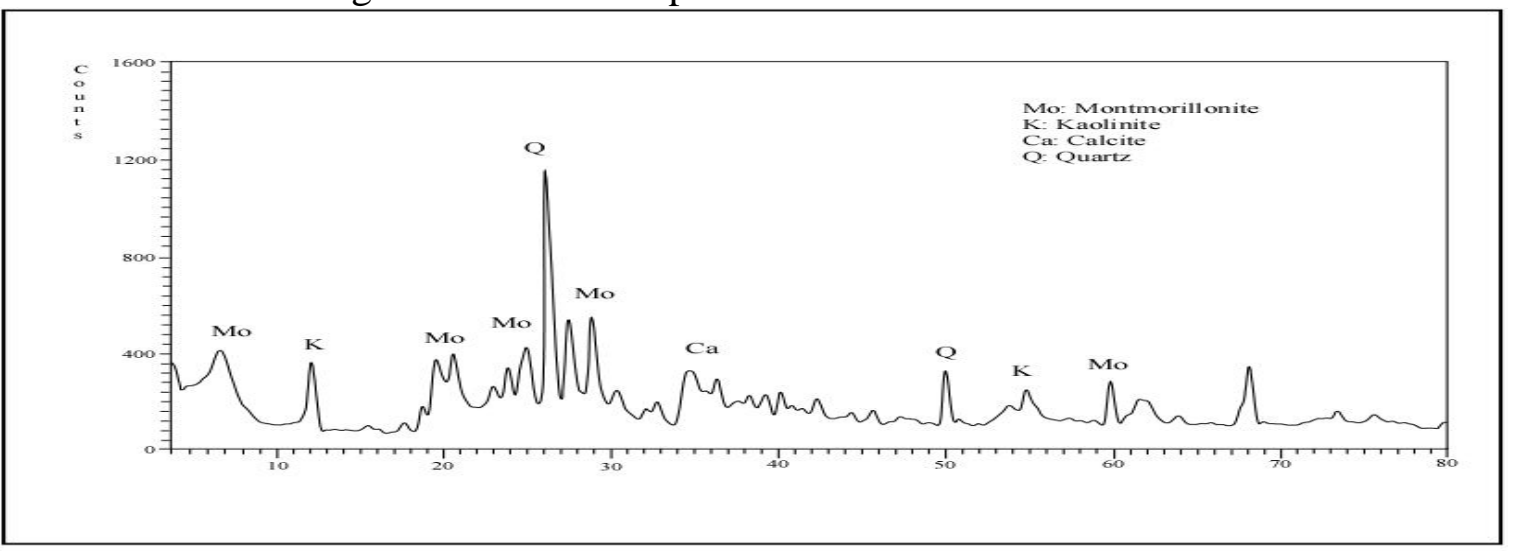

Figure 4: The XRD spectrum of Alizarin impregnated activated bentonite

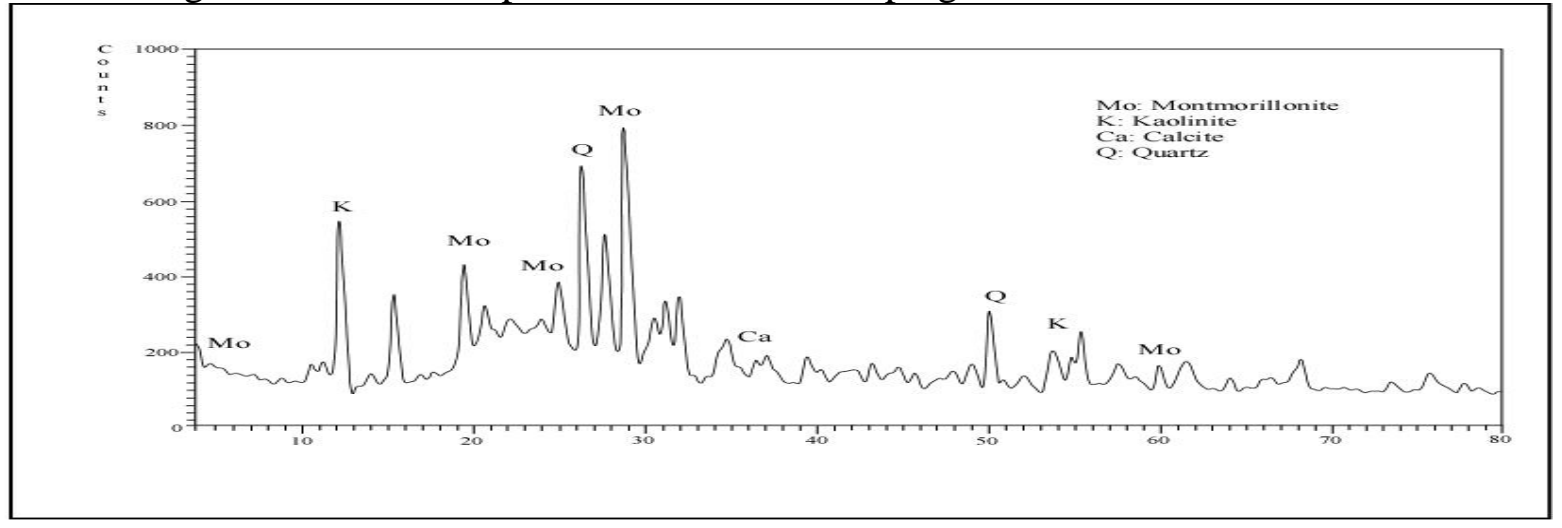

Figure 5: The XRD spectrum of Alizarin impregnated activated bentonite with metal impurities.

\subsubsection{SEM-EDX analysis}

In order to compare the surface morphologies of changes before and after impregnation of solvent on solid adsorbent and impurities removal from WPPA, it was simultaneously conducted SEM and EDX analyzes in the current study. The scanning electron micrograph of natural bentonite, activated bentonite, and Alizarin impregnated activated bentonite, as well as the loaded impurities on AIAB from WPPA, are given in Figures (6-9). Natural and activated bentonite exhibited varying sizes and some are composed of flakes (Figures 6, 7). Agglomeration and rough surfaces could be observed after Alizarin impregnation activated bentonite (Figure 8) while the surfaces became more compact after 
metal impurities adsorption and the micrograph showed different shapes for the particles with greater size and low aggregates and porous structure due to the presence of the impurities (Figure 9).

EDX analysis revealed that almost metal ions are released from natural bentonite which is treated with $1 \mathrm{M} \mathrm{H}_{2} \mathrm{SO}_{4}$ to obtain activated bentonite (Figures 6, 7).

EDX spectrums of Alizarin impregnated activated bentonite appears carbon and oxygen atoms at the spectrum, Alizarin had been first impregnated in the interlayer of activated bentonite by silanol or aluminol groups and $\mathrm{H}_{2} \mathrm{O}$ is released (Figures 8).

EDX spectrums of the loaded impurities on Alizarin impregnated activated bentonite are adsorbed some metal impurities from wet process phosphoric acid. The presence of phosphor ions in Figure (9) may confirm that the metal impurities are adsorbed on the surface of solvent impregnated bentonite as metal complex cation $\left[\left(\mathrm{MH}_{2} \mathrm{PO}_{4}\right)^{\mathrm{n}+}\right]$.

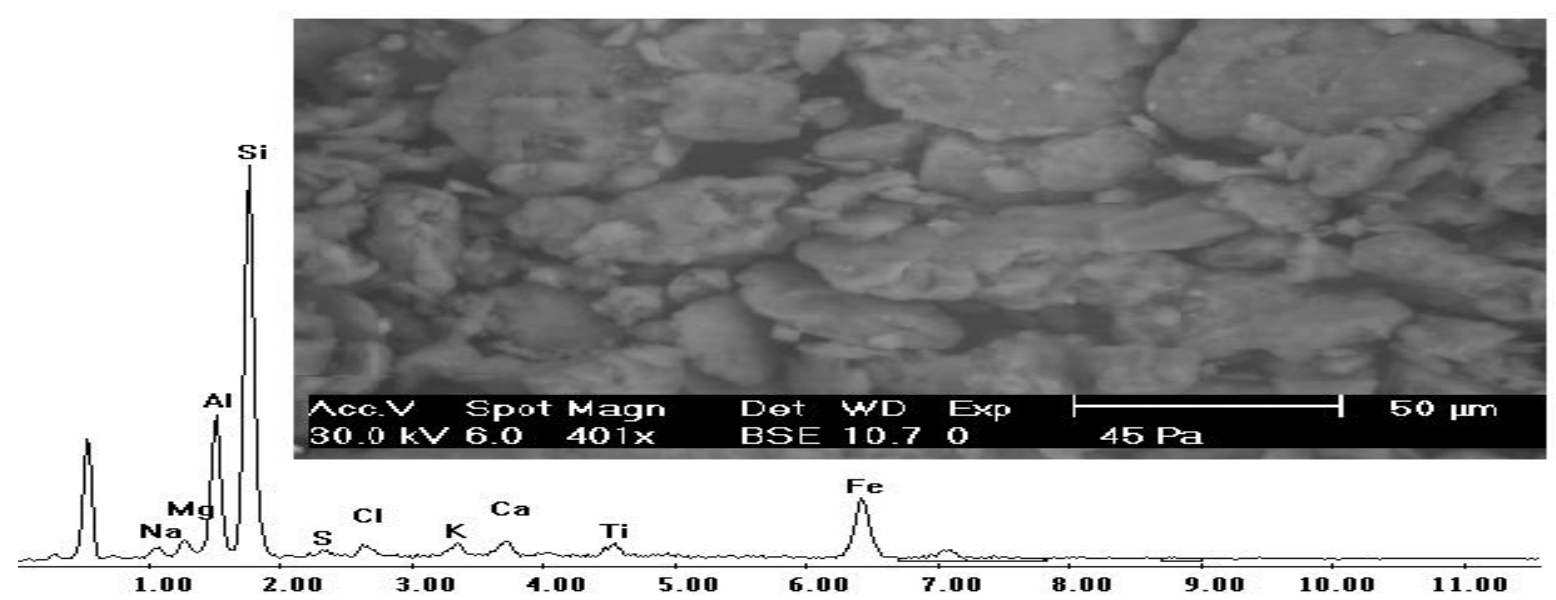

Figure 6: The scanning electron microscope, and the corresponding EDX spectrum of natural bentonite.

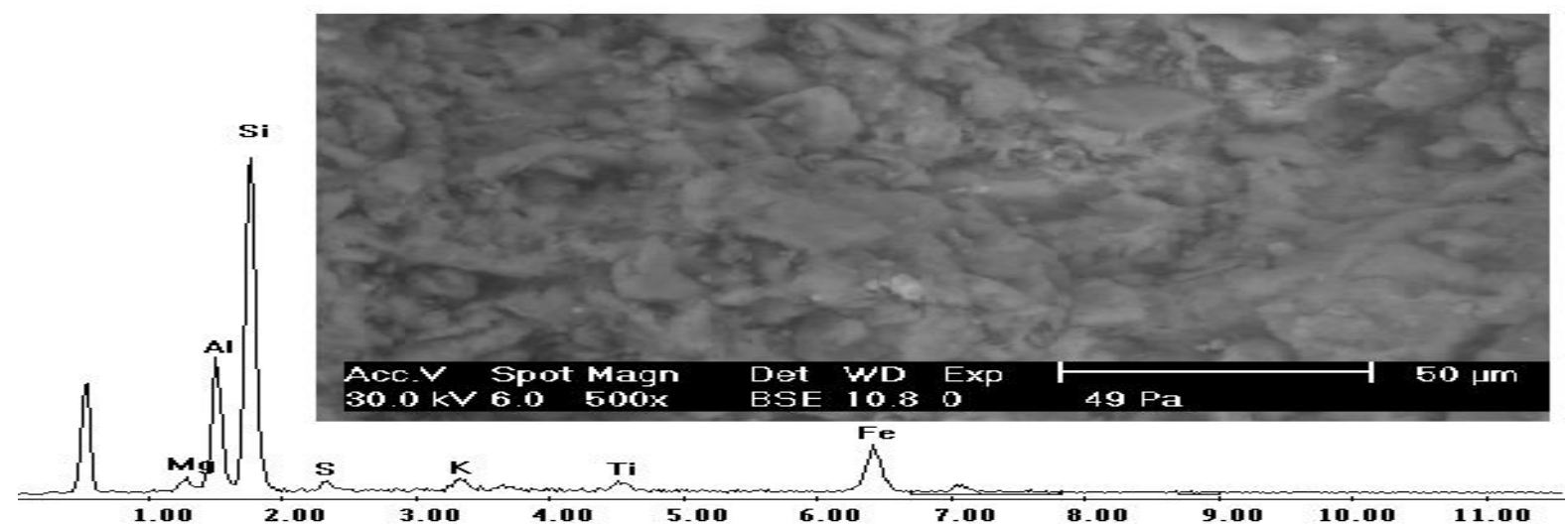

Figure 7: The scanning electron microscope, and the corresponding EDX spectrum of activated bentonite. 


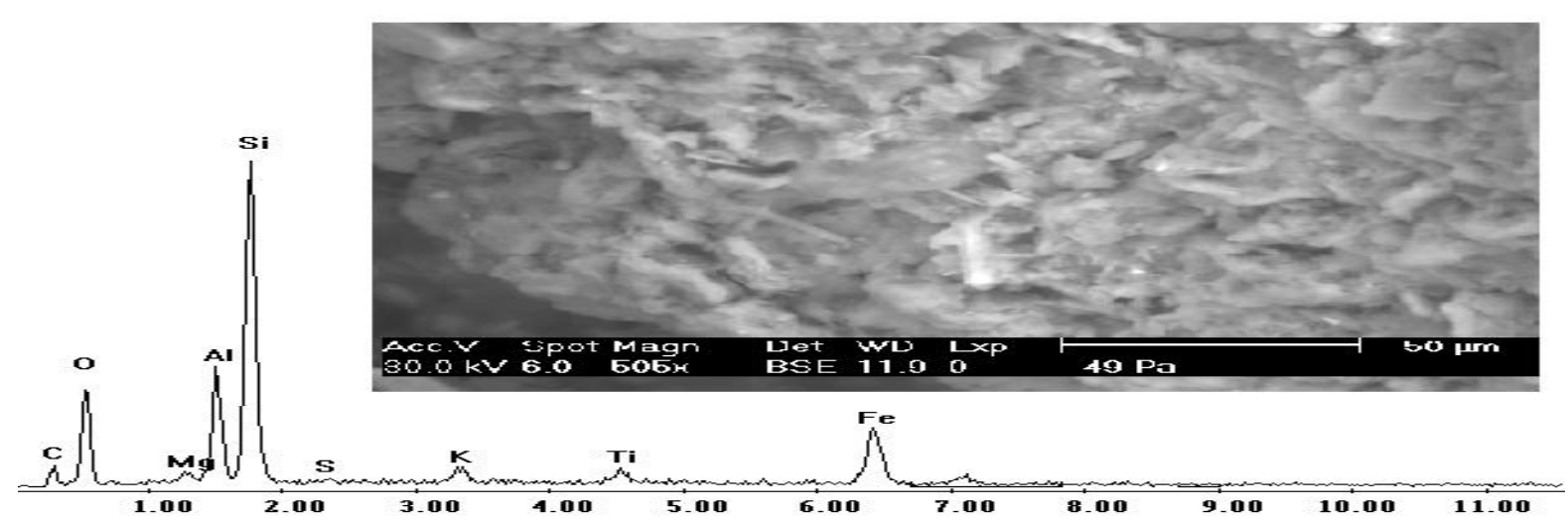

Figure 8: The scanning electron microscope and the corresponding EDX spectrum of Alizarin impregnated activated bentonite.

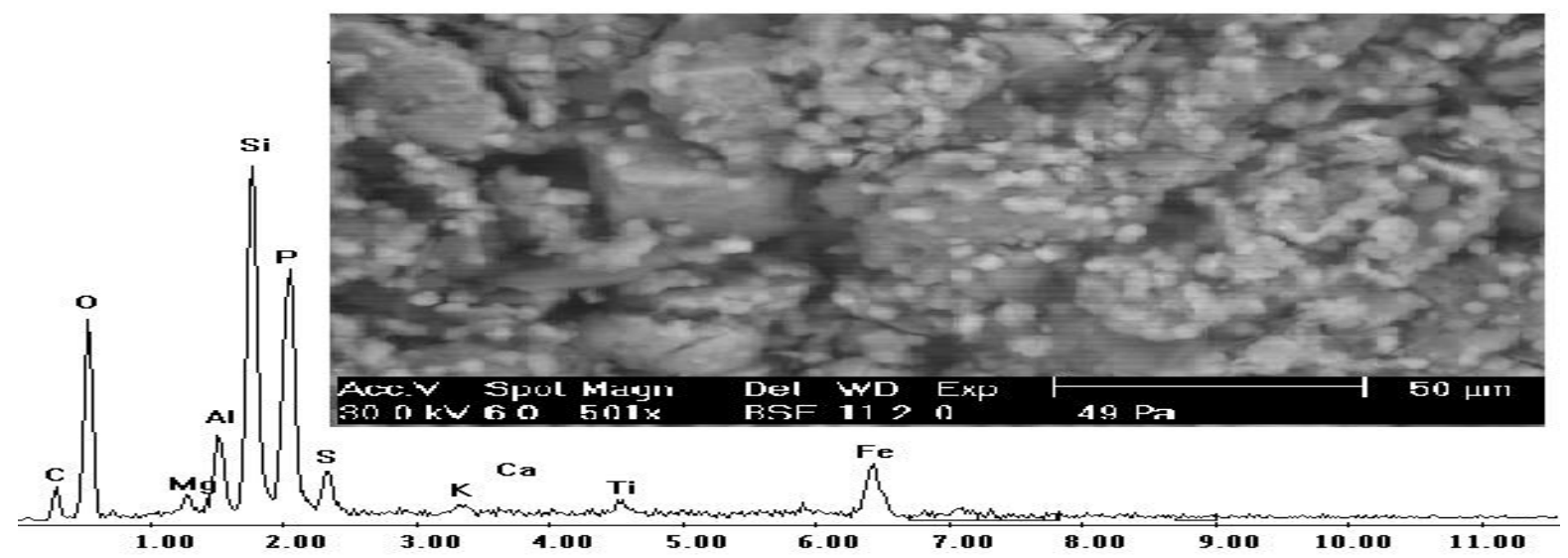

Figure 9: The scanning electron microscope and the corresponding EDX spectrum of the loaded impurities on Alizarin impregnated activated bentonite.

\subsubsection{FT-IR spectrum analysis}

The FT-IR spectrum analysis for natural bentonite, activated bentonite, Alizarin, and Alizarin impregnated activated bentonite as well as cation impurities loaded on AIAB are carried out and given in Figures $(10-14)$ respectively.

The characteristic vibration peaks of natural and activated bentonite appeared at 3407 $\mathrm{cm}^{-1}$ for the merging SiO-H or AlO-H stretching (Figures 10, 11). The vibration peaks 1034 $\mathrm{cm}^{-1}$ and $440 \mathrm{~cm}^{-1}$ were observed for $\mathrm{Si}-\mathrm{O}$ stretching and bending respectively indicated tetrahedral bending mode while the vibration bands at $927 \mathrm{~cm}^{-1}$ and $529 \mathrm{~cm}^{-1}$ for $\mathrm{Al}-\mathrm{O}$ stretching and bending respectively are corresponding to octahedral mode (Duan and Evans, 2006; Forano et al., 2006).

The characteristic vibration bands of Alizarin are observed at $3499 \mathrm{~cm}^{-1}$ (-OH stretching), $3084 \mathrm{~cm}^{-1}$ (-CH aromatic stretching), $1068 \mathrm{~cm}^{-1}$, (C-O stretching) (Figure 12). The $-\mathrm{OH}$ stretching peaks of Alizarin at $3499 \mathrm{~cm}^{-1}$ and $\mathrm{SiO}-\mathrm{H}$ bond of activated bentonite at $3387 \mathrm{~cm}^{-1}$ are merged and shifted to $3377 \mathrm{~cm}^{-1}$ in the case of impregnation with activated bentonite (Abdou et al., 2013). The band of $\mathrm{C}=\mathrm{O}$ of Alizarin in $1666 \mathrm{~cm}^{-1}$ is shifted to 1642 $\mathrm{cm}^{-1}$ in the case of impregnation. This phenomenon reveals that the above shifting behavior occurs due to inter-molecular and intra-molecular H-bonding interactions (Figure 13).

In case of the loaded impurities on Alizarin impregnated activated bentonite (Figure 14), the vibration peaks appeared at lower wavenumber due to the shifting in the direction of 
the red shift. This indicates that the metal impurities are adsorbed on the surface of impregnated bentonite.

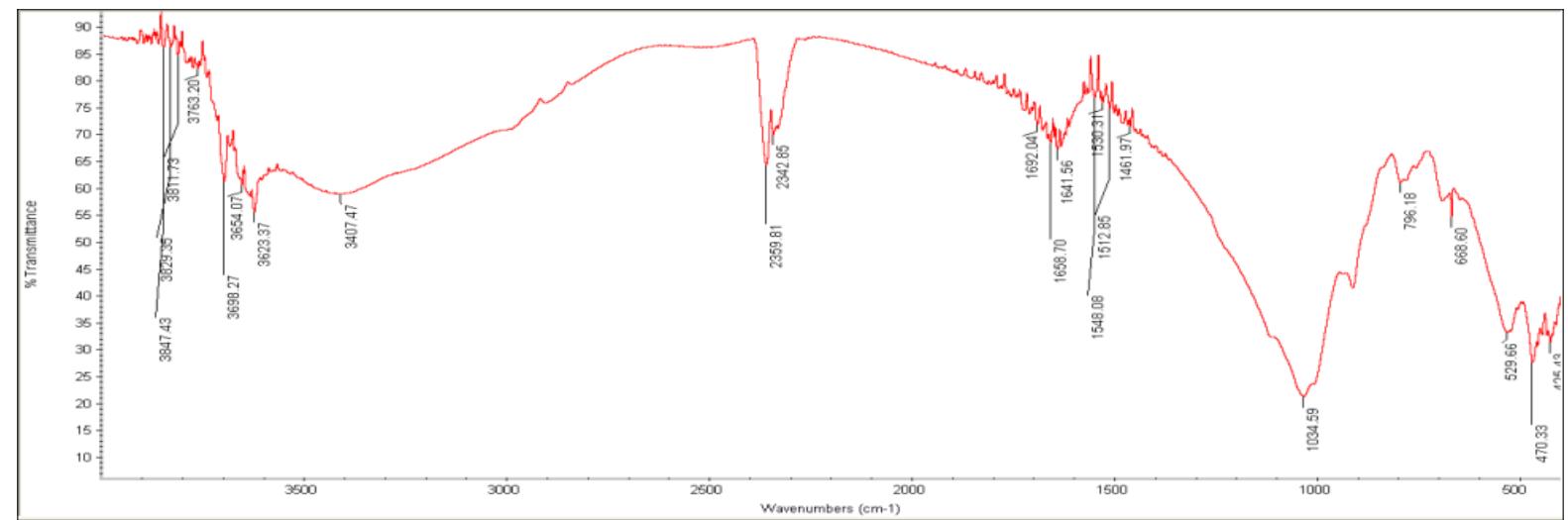

Figure 10: FT-IR spectrum of natural bentonite.

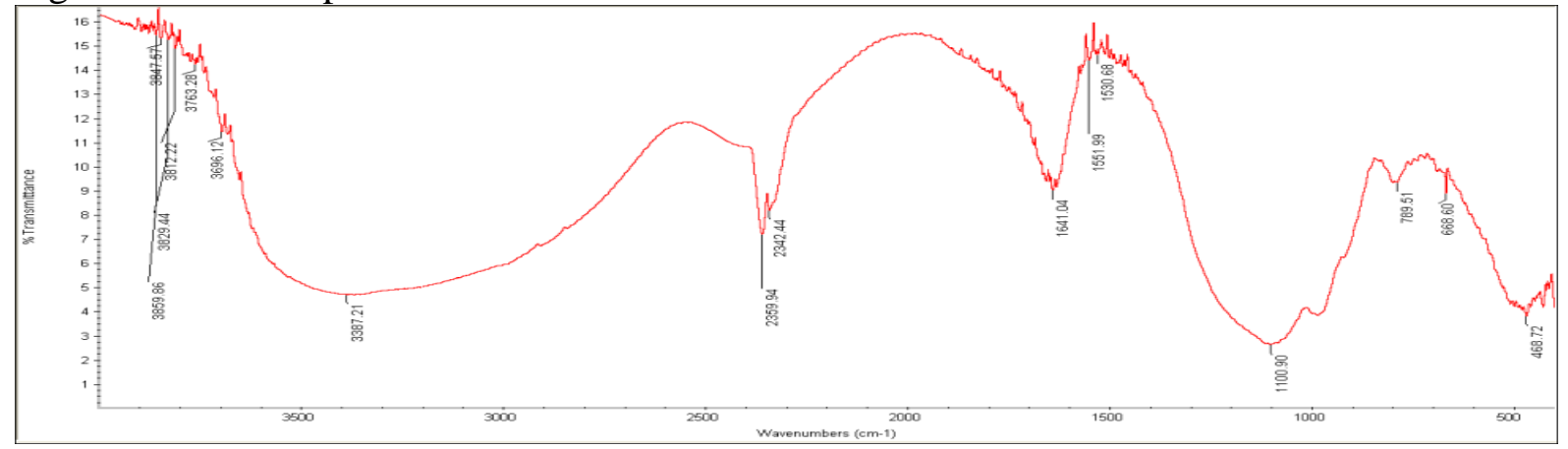

Figure 11: FT-IR spectrum of activated bentonite.

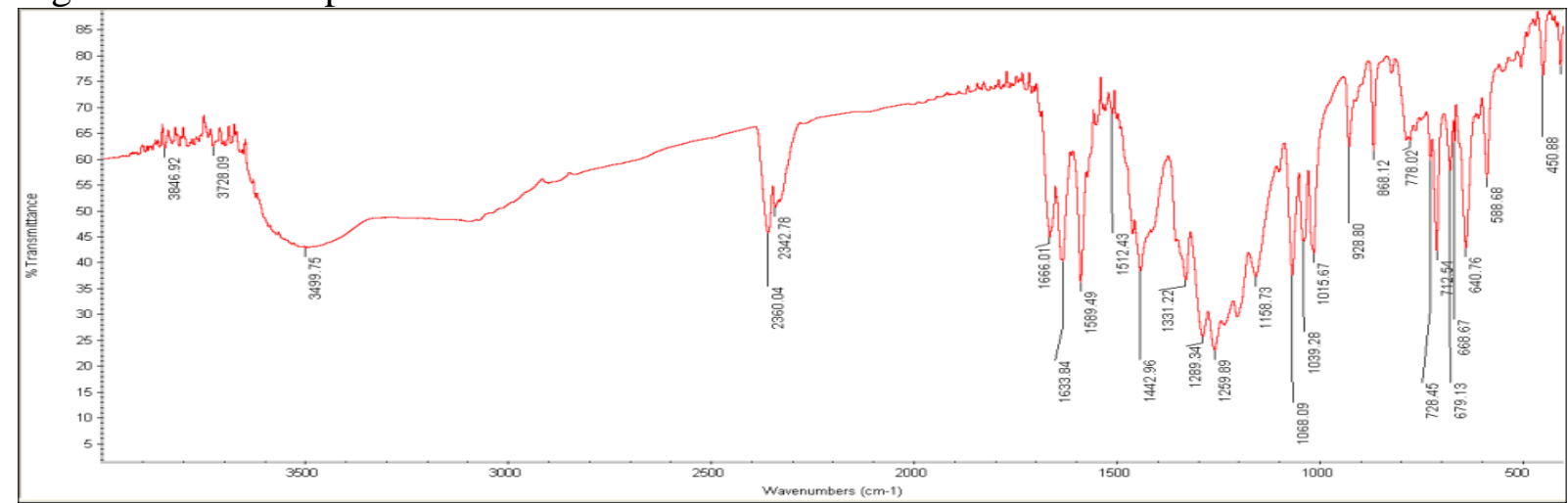

Figure 12: FT-IR spectrum of Alizarin.

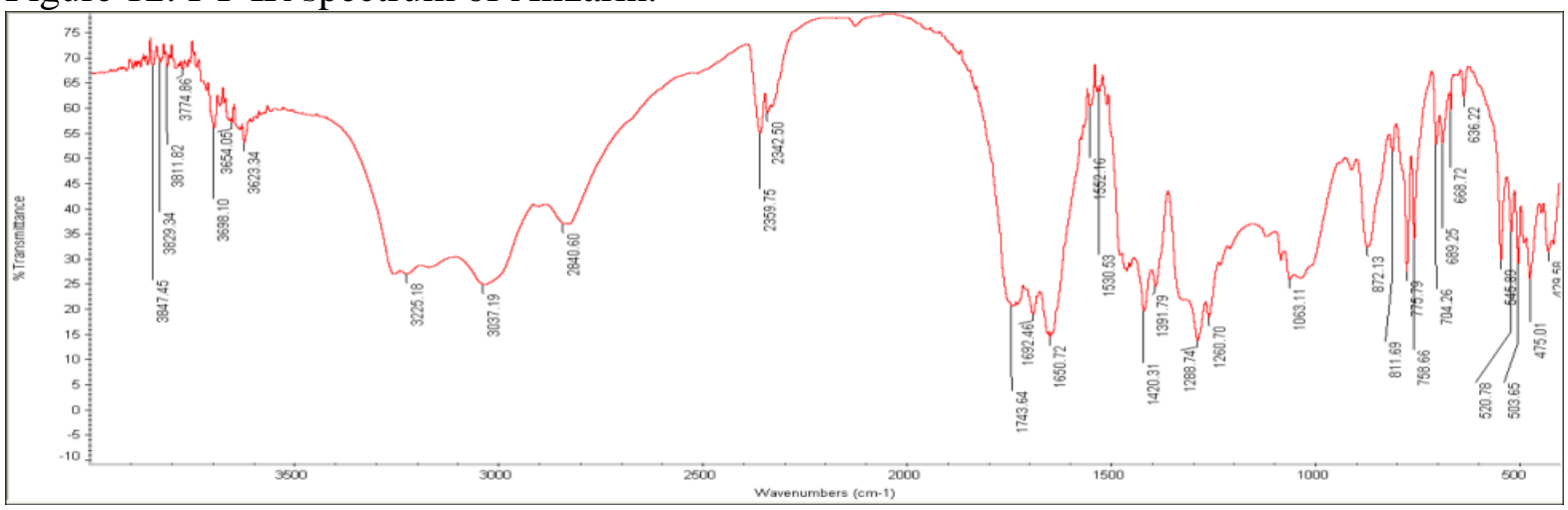

Figure 13: FT-IR spectrum of Alizarin impregnated activated bentonite. 


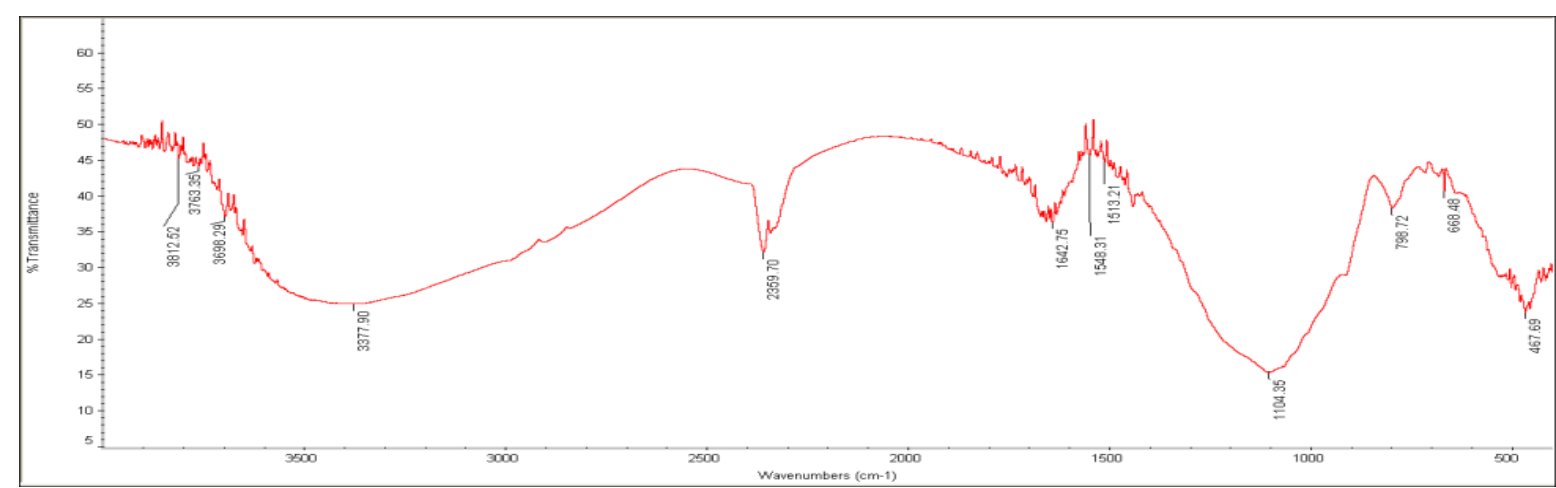

Figure 14: FT-IR spectrum of the loaded impurities on Alizarin impregnated activated bentonite.

Finally, the suggested mechanisms of the metal impurities loaded on Alizarin impregnated activated bentonite from WPPA $\left(5 \mathrm{M} \mathrm{H}_{3} \mathrm{PO}_{4}\right)$ are illustrated in the following Schemes (1):
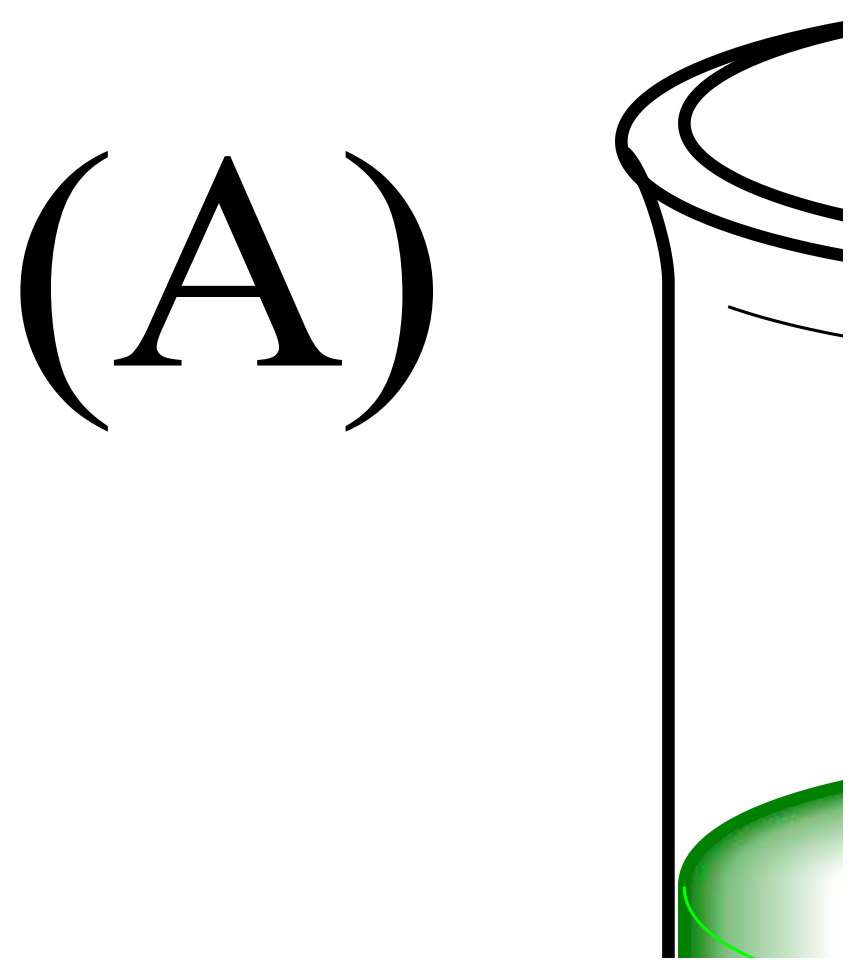

Scheme 1: Proposed mechanism of (A) clarified WPPA, (B) Alizarin impregnated activated bentonite, and (C) metal ions impurities loaded on AIAB. 


\subsection{Metal impurities removal investigations}

In the existing study, the $\mathrm{Pb}^{2+}, \mathrm{Ni}^{2+}$, and $\mathrm{Zn}^{2+}$ ions are removed from a synthetic solution of phosphoric acid as metal ions phosphate complexes on the surface of Alizarin impregnated activated bentonite (AIAB) as adsorbent material. Several sets of equilibrium experiments have been conducted upon the individual metal ions removal efficiency to optimize the effect of acid concentration, contact time, adsorbent dose, initial metal ions concentration, and temperature.

\subsubsection{Effect of acid concentration}

The influence of phosphoric acid concentrations on the removal of the individual $\mathrm{Pb}^{2+}$, $\mathrm{Ni}^{2+}$, and $\mathrm{Zn}^{2+}$ ions by AIAB adsorbent is carried out at different concentrations from 1 to 8 $\mathrm{M} \mathrm{H}_{3} \mathrm{PO}_{4}$ and the other experimental conditions are fixed at $50 \mathrm{mg}$ adsorbent and $50 \mathrm{ml}$ of synthetic acid assaying $150 \mathrm{mg} / \mathrm{L}$ of individual metal ions for $60 \mathrm{~min}$ contact time at room temperature.

From the data in Figure (15), the removal efficiencies of $\mathrm{Pb}^{2+}, \mathrm{Ni}^{2+}$, and $\mathrm{Zn}^{2+}$ ions are slightly decreased from $83.00,58.40$, and $98.00 \%$ to $81.00,55.00$, and $94.47 \%$ respectively with increasing the acid concentrations from 1 to $5 \mathrm{M}$. Subsequently, the increases of the acid concentrations up to $8 \mathrm{M}$ are sharply decreased the removal efficiencies to $58.40,35.50$, and $67.89 \%$ for $\mathrm{Pb}^{2+}, \mathrm{Ni}^{2+}$, and $\mathrm{Zn}^{2+}$ ions respectively. Thus, the removal efficiencies of the studied metal impurities at $5 \mathrm{M}$ acid concentration which is equivalent to WPPA concentrations are selected in the next experiments.

The active surface groups at the Alizarin impregnated activated bentonite have been explored as silanol $(\mathrm{Si}-\mathrm{OH})$, and aluminol $(\mathrm{Al}-\mathrm{OH})$ sites, which form the main constituents of this type of the bentonite clay $\left(\mathrm{SiO}_{2}\right.$ and $\left.\mathrm{Al}_{2} \mathrm{O}_{3}\right)$, as well as each molecule of Alizarin contains two hydroxyl groups. In other words, AIAB has a large negative net charge. Thus, it tends to electrostatically attract any positive ions (cations) to its surface. This adsorption behavior could be inductive of inner sphere complexation or sorption to its sites owning negative charge. The oxygen atoms present on the impregnated bentonite surface in aqueous solution form complex ions by bonding with positive ions.

At 1-5 M phosphoric acid, the surface of AIAB will become slightly covered with $\mathrm{H}^{+}$ ions, where silanol, aluminol, and hydroxyl groups are less protonated due to the presence of anion complexes of phosphate complex which easily reacts with the hydronium ions. Accordingly, metal complex cations can easily adsorb with the active sites of the impregnated bentonite according to the following equations.

At the higher concentration, $>5 \mathrm{M}$ of $\mathrm{H}_{3} \mathrm{PO}_{4}$ may indicate that the lower metal sorption efficiency detected due to the active oxygen atoms of hydroxyl groups of the Alizarin impregnated activated bentonite, and silanol, as well as aluminol groups on the bentonite surface, are protonated with hydrogen cations. 


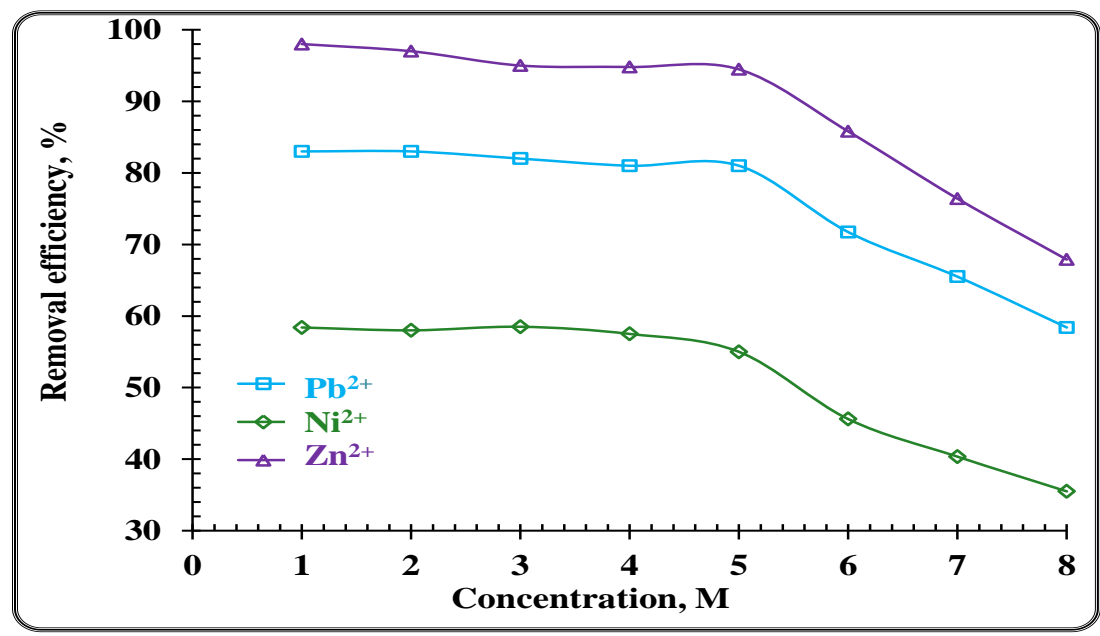

Figure 15: Effect of acid concentrations on the removal efficiencies of the studied metal impurities in $\mathrm{H}_{3} \mathrm{PO}_{4}$ by AIAB $(50 \mathrm{ml}$ of $150 \mathrm{mg} / \mathrm{L}$ of individual metal ions concentration, 50 $\mathrm{mg}$ adsorbent dose, 60 min contact time, room temperature).

\subsubsection{Effect of contact time}

The effect of contact time on the removal efficiencies of the individual $\mathrm{Pb}^{2+}, \mathrm{Ni}^{2+}$, and $\mathrm{Zn}^{2+}$ ions for AIAB adsorbent are investigated at different contact time variable from 5 to 120 min while the other experimental settings are used at $50 \mathrm{mg}$ adsorbent dose and $50 \mathrm{ml}$ of $5 \mathrm{M}$ synthetic acid assaying $150 \mathrm{mg} / \mathrm{L}$ of individual metal ions at room temperature.

As accessible in the Figure (16), the removal efficiencies of $\mathrm{Pb}^{2+}, \mathrm{Ni}^{2+}$, and $\mathrm{Zn}^{2+}$ ions on the studied adsorbent are increased from $26.78,19.53$, and $33.44 \%$ to $81.00,55.00$, and $94.47 \%$ with increasing the contact time from $5 \mathrm{~min}$ until reaches equilibrium after about 60 min respectively. Whereas, shifting the contact time up to $120 \mathrm{~min}$ has no noticeable influence on the adsorption efficiencies of the studied metal ions. Consequently, the contact time of $60 \mathrm{~min}$ is considered for further optimizing condition.

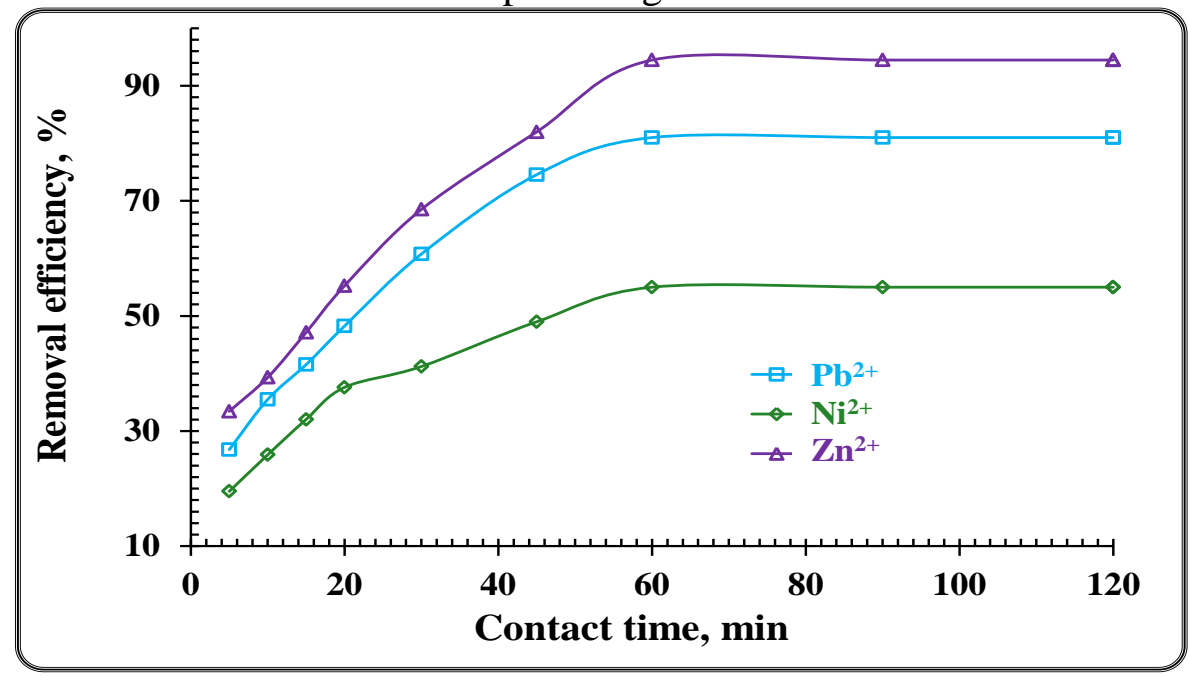

Figure 16: Effect of contact time on the removal efficiencies of the studied metal impurities in $\mathrm{H}_{3} \mathrm{PO}_{4}$ by AIAB adsorbent $\left(50 \mathrm{ml}\right.$ of $5 \mathrm{M} \mathrm{H}_{3} \mathrm{PO}_{4}$ assaying $150 \mathrm{mg} / \mathrm{L}$ of individual metal ions, $0.05 \mathrm{~g}$ adsorbent dose, room temperature). 


\subsection{Effect of adsorbent dose}

In this study, the effect of adsorbent dose on the removal of the individual $\mathrm{Pb}^{2+}, \mathrm{Ni}^{2+}$, and $\mathrm{Zn}^{2+}$ ions by AIAB adsorbent are achieved using the AIAB adsorbent in the dose range from 10 to $400 \mathrm{mg}$ under the $50 \mathrm{ml}$ of $5 \mathrm{M}$ synthetic $\mathrm{H}_{3} \mathrm{PO}_{4}$ containing $150 \mathrm{mg} / \mathrm{L}$ of individual studied metal impurities for 60 min contact time at room temperature.

The effect of adsorbent dose is predicted in terms of both removal efficiency and uptake capacity $\left(\mathrm{q}_{\mathrm{e}}\right)$. The obtained results shown in Figures $(17,18)$, reveal that the removal efficiencies have increased with increasing the adsorbent where at higher dose; more ions exchange sites are available for ion exchange procedures due to increasing the surface area. Hence, the removal efficiencies of $\mathrm{Pb}^{2+}, \mathrm{Ni}^{2+}$, and $\mathrm{Zn}^{2+}$ ions are increased from 16.20, 11.00, and $18.89 \%$ to $98.00,95.00$, and $99.00 \%$ respectively with increasing the adsorbent dose from 10 to $80 \mathrm{mg}$ for AIAB. However, the adsorption efficiencies have remained constant thereafter till $100 \mathrm{mg}$. The equivalent uptake capacities of $\mathrm{Pb}^{2+}, \mathrm{Ni}^{2+}$, and $\mathrm{Zn}^{2+}$ ions are thus decreased from $121.50,82.50$, and $141.70 \mathrm{mg} / \mathrm{g}$ to $91.00,82.50$, and $95.00 \mathrm{mg} / \mathrm{g}$ at $80 \mathrm{mg}$, as well as down to $73.00,70.00$, and $75.00 \mathrm{mg} / \mathrm{g}$ respectively at $100 \mathrm{mg}$ adsorbent dose. Thus, the $50 \mathrm{mg}$ adsorbent dose is selected in the successive experiments.

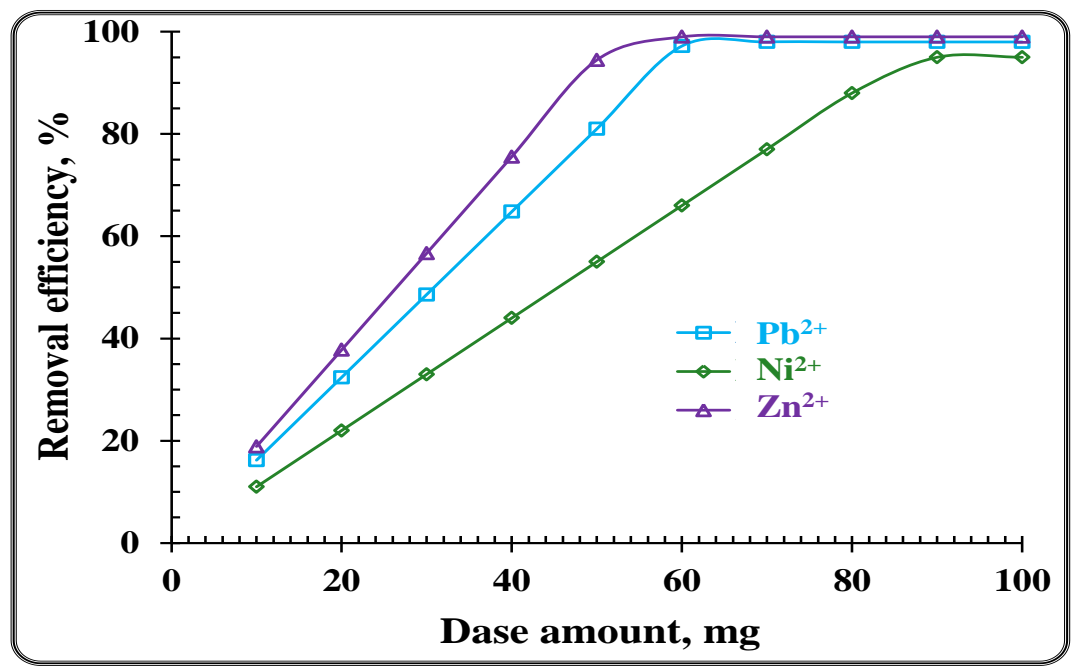

Figure 17: Effect of adsorbent dose on the removal efficiencies of the studied metal ions impurities in $\mathrm{H}_{3} \mathrm{PO}_{4}\left(50 \mathrm{ml}\right.$ of $5 \mathrm{M} \mathrm{H}_{3} \mathrm{PO}_{4}$ assaying $150 \mathrm{mg} / \mathrm{L}$ of individual metal ions, $60 \mathrm{~min}$ contact time, room temperature).

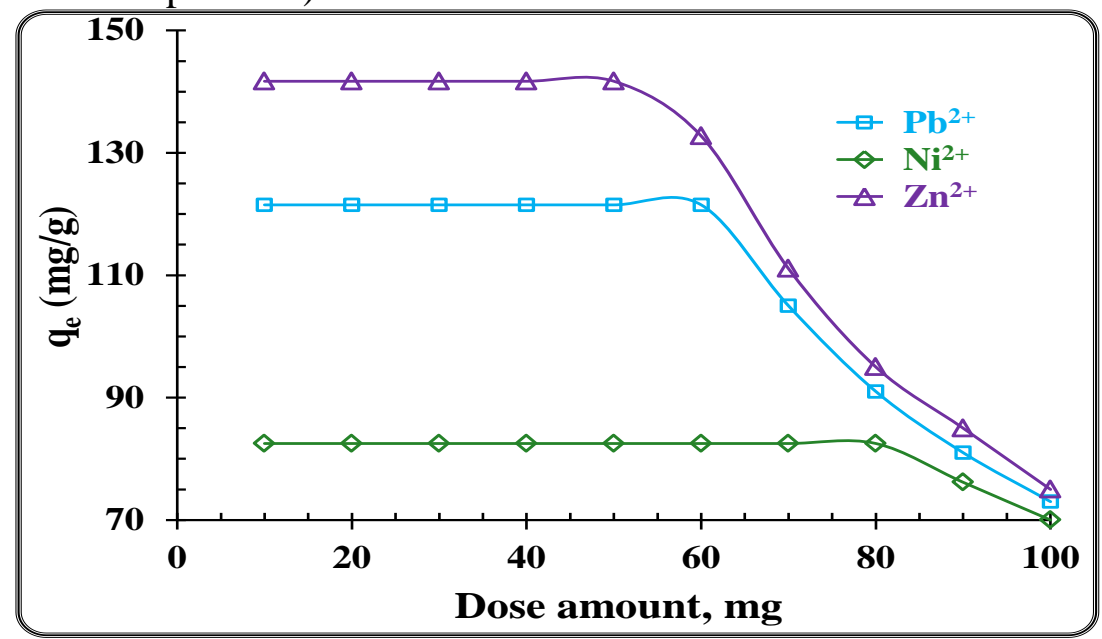


Figure 18: Effect adsorbent dose on the uptake capacities of the studied metal ions impurities in $\mathrm{H}_{3} \mathrm{PO}_{4}\left(50 \mathrm{ml}\right.$ of $5 \mathrm{M} \mathrm{H}_{3} \mathrm{PO}_{4}$ assaying $150 \mathrm{mg} / \mathrm{L}$ of individual metal ions, $60 \mathrm{~min}$ contact time, room temperature).

\subsubsection{Effect of initial metal ions concentration}

Effect of individual initial metal ions concentration is the most important parameters on the sorption system, which can influence the sorption behavior of metal ions on the studied adsorbent. Several batch experiments are done to describe the effect of changing the initial metal ions concentration on the removal efficiencies of $\mathrm{Pb}^{2+}, \mathrm{Ni}^{2+}$, and $\mathrm{Zn}^{2+}$ ions by AIAB adsorbent. These experiments are carried out by shaking $50 \mathrm{ml}$ of the $5 \mathrm{M}$ synthetic $\mathrm{H}_{3} \mathrm{PO}_{4}$ solution containing the individual studied metal ions in the range of 25 to $800 \mathrm{mg} / \mathrm{L}$ at $50 \mathrm{mg}$ of AIAB adsorbents for 60 min contact time at room temperature.

The results plotted in Figures $(19,20)$ reveal that the initially studied metal ions concentrations are increased and the amount of metal ions uptakes $\left(\mathrm{q}_{\mathrm{e}}\right.$ in $\left.\mathrm{mg} / \mathrm{g}\right)$ are also increased as well as the maximum removal efficiencies are obtained at $150 \mathrm{mg} / \mathrm{L}$ initial individual metal ions concentrations. The removal efficiencies at $150 \mathrm{mg} / \mathrm{L}$ initial concentration of $\mathrm{Pb}^{2+}, \mathrm{Ni}^{2+}$, and $\mathrm{Zn}^{2+}$ ions are 81.00, 55.00, and 94.47\% respectively, therefore, the $\mathrm{Pb}^{2+}, \mathrm{Ni}^{2+}$, and $\mathrm{Zn}^{2+}$ ions removal capacities on AIAB adsorbent are 121.50, 82.50 , and $141.70 \mathrm{mg} / \mathrm{g}$, respectively. After that, the removal amounts of the studied metal ions have remained constant expressing that the working adsorbent has reached to its maximum loading capacity (saturation capacity). Because the mobility of divalent metal ions complexes $\mathrm{M}\left(\mathrm{H}_{2} \mathrm{PO}_{4}\right)^{+}$in the solutions is the highest and all active sites of the adsorbent are filled and blocked with metal ions from the solution.

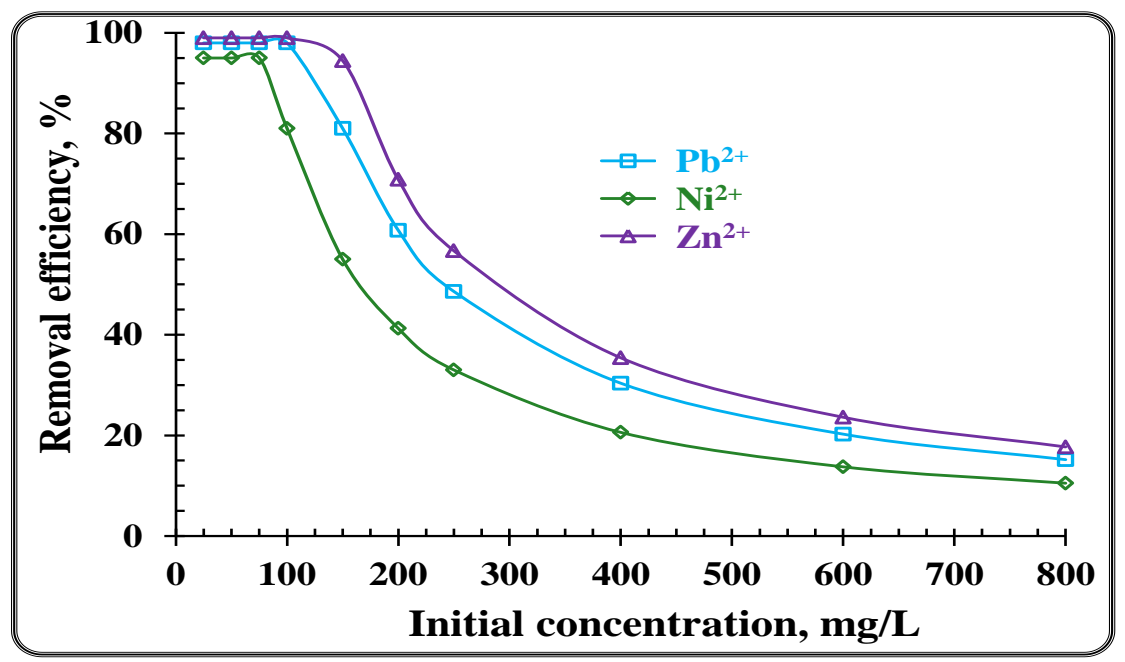

Figure 19: Effect of initial individual metal ions concentrations on the removal efficiencies of the studied metal ions impurities in $\mathrm{H}_{3} \mathrm{PO}_{4}\left(50 \mathrm{ml}\right.$ of $5 \mathrm{M} \mathrm{H}_{3} \mathrm{PO}_{4}, 50 \mathrm{mg}$ adsorbent, $60 \mathrm{~min}$ contact time, room temperature). 


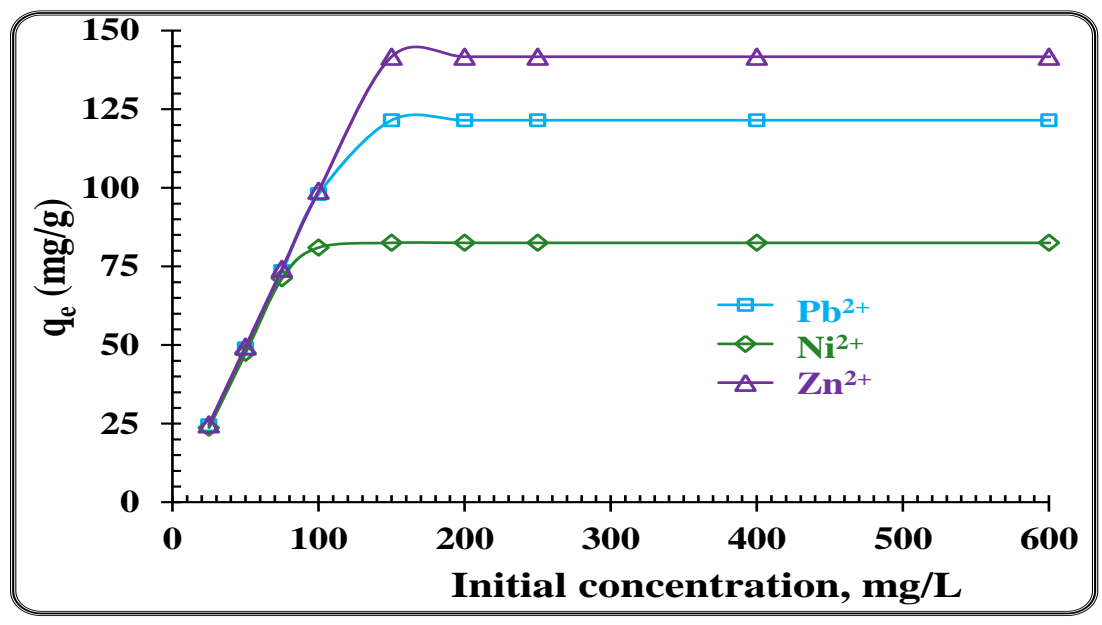

Figure 20: Effect of initial individual metal ions concentrations on the uptake capacities of the studied metal ions impurities in $\mathrm{H}_{3} \mathrm{PO}_{4}\left(50 \mathrm{ml}\right.$ of $5 \mathrm{M} \mathrm{H}_{3} \mathrm{PO}_{4}, 50 \mathrm{mg}$ adsorbent, 60 min contact time, room temperature).

\subsubsection{Effect of temperature}

The effect of temperature on the removal efficiencies and uptake capacities of $\mathrm{Pb}^{2+}$, $\mathrm{Ni}^{2+}$, and $\mathrm{Zn}^{2+}$ ions are fulfilled by AIAB adsorbent in the range $25-55{ }^{\circ} \mathrm{C}$ under all other above optimum parameters are kept constant. The results are exposed in Table (3), the temperature is elevated from 25 to $55^{\circ} \mathrm{C}$, the removal efficiencies of $\mathrm{Pb}^{2+}, \mathrm{Ni}^{2+}$, and $\mathrm{Zn}^{2+}$, ions are reduced from 81.0, 55.0, and $94.5 \%$ to $79.9,53.9$, and $93.4 \%$ at 25 to $55{ }^{\circ} \mathrm{C}$, as well as the uptake capacities are also reduced from $121.5,82.5$, and $141.7 \mathrm{mg} / \mathrm{g}$ at $25{ }^{\circ} \mathrm{C}$ to 119.8 , 80.8 , and $140.1 \mathrm{mg} / \mathrm{g}$ at $55{ }^{\circ} \mathrm{C}$ for AIAB adsorbent respectively. According to this result implied that the reaction is not related to energy and it is an exothermic reaction. Accordingly, the room temperature is the optimum temperature for adsorption metal ions impurities on AIAB adsorbent.

Table 3: Effect of temperature on the removal efficiencies and uptake capacities of the studied metal ions impurities in $\mathrm{H}_{3} \mathrm{PO}_{4}$

\begin{tabular}{|c|ccc|ccc|}
\hline \multirow{2}{*}{ Temp., } & $\mathbf{0}$ & \multicolumn{3}{|c|}{ Removal efficiency, \% } & \multicolumn{3}{c|}{$\mathbf{q}_{\mathbf{e}}(\mathbf{m g} \mathbf{g})$} \\
\cline { 2 - 7 } & $\mathbf{P b}^{\mathbf{2 +}}$ & $\mathbf{N i}^{\mathbf{2 +}}$ & $\mathbf{Z n}^{\mathbf{2 +}}$ & $\mathbf{P b}^{\mathbf{2 +}}$ & $\mathbf{N i}^{\mathbf{2}}$ & $\mathbf{Z n}^{\mathbf{2 +}}$ \\
\hline $\mathbf{2 5}$ & 81.0 & 55.0 & 94.5 & 121.5 & 82.5 & 141.7 \\
$\mathbf{3 0}$ & 80.9 & 54.9 & 94.3 & 121.3 & 82.3 & 141.4 \\
$\mathbf{3 5}$ & 80.8 & 54.8 & 94.2 & 121.2 & 82.2 & 141.3 \\
$\mathbf{4 0}$ & 80.6 & 54.6 & 94.1 & 120.9 & 81.9 & 141.1 \\
$\mathbf{4 5}$ & 80.4 & 54.4 & 93.8 & 120.6 & 81.6 & 140.7 \\
$\mathbf{5 0}$ & 80.2 & 54.1 & 93.6 & 120.3 & 81.1 & 140.4 \\
$\mathbf{5 5}$ & 79.9 & 53.9 & 93.4 & 119.8 & 80.8 & 140.1 \\
\hline
\end{tabular}

\subsection{Regeneration and reusability}

Regeneration is the reinforced aspects in the applicability of the adsorbents. To recycle the studied adsorbent, the metal ions loaded studied adsorbent are renewed using $0.5 \mathrm{M}$ sulfuric acid solution, and 1:75 S:L phase ratio, at room temperature for 30 min contact time. The adsorption-desorption procedures are repeated the number of times up to desorption efficiencies are reduced from $98 \%$ to $82 \%$ for the studied adsorbent after five consecutive cycles, which are indicated that the good adsorption stability of the AIAB adsorbent for $\mathrm{Pb}^{2+}$, $\mathrm{Ni}^{2+}$, and $\mathrm{Zn}^{2+}$ ions. 


\subsection{Removal studies for real WPPA}

Alizarin impregnated activated bentonite (AIAB) is used for the eliminating of $\mathrm{Pb}^{2+}$, $\mathrm{Ni}^{2+}$, and $\mathrm{Zn}^{2+}$ ions as metal ions phosphate complexes from wet process phosphoric acid (5 $\mathrm{M} \mathrm{H}_{3} \mathrm{PO}_{4}, 29 \% \mathrm{P}_{2} \mathrm{O}_{5}$ ). The equilibrium concentrations of the studied elements are determined in the filtrate using AAS technique. The removal parameters are studied on WPPA to optimize the contact time, adsorbent dose, acid volume, and temperature.

\subsubsection{Effect of contact time}

The data for the removal of the $\mathrm{Pb}^{2+}, \mathrm{Ni}^{2+}$, and $\mathrm{Zn}^{2+}$ ions by AIAB adsorbent at different contact time alternating from 15 to 120 min under the experimental conditions which are $50 \mathrm{~mL}$ of WPPA, and $150 \mathrm{mg}$ of AIAB at $25{ }^{\circ} \mathrm{C}$ solution temperature are studied. The results in Figure (21) show that after $60 \mathrm{~min}$, the removal efficiencies of $\mathrm{Pb}^{2+}, \mathrm{Ni}^{2+}$, and $\mathrm{Zn}^{2+}$ ions are 95.9, 89.2, and $99.5 \%$ respectively. Accordingly, $60 \mathrm{~min}$ contact time is enough to achieve the equilibrium time for removal of all metal ions on the surface of AIAB.

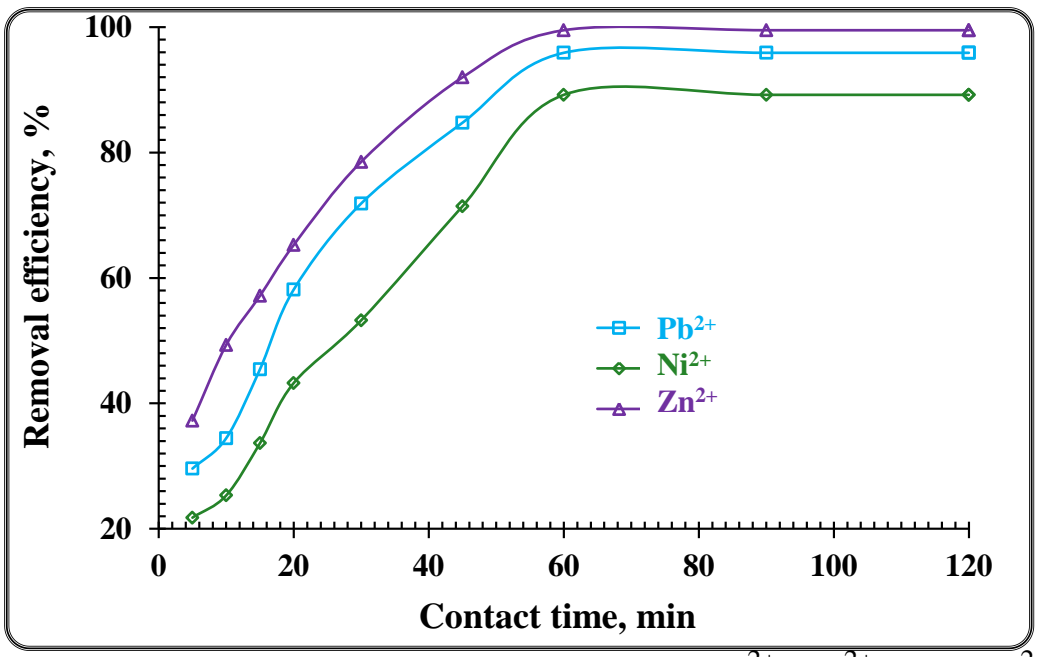

Figure 21: Effect of contact time on the removal of the $\mathrm{Pb}^{2+}, \mathrm{Ni}^{2+}$, and $\mathrm{Zn}^{2+}$ ions by AIAB adsorbent from WPPA.

\subsubsection{Effect of adsorbent amount}

The removal of the $\mathrm{Pb}^{2+}, \mathrm{Ni}^{2+}$, and $\mathrm{Zn}^{2+}$ ions from WPPA at different amount of AIAB adsorbent $(30-250 \mathrm{mg})$ under the above experimental conditions are performed and characterized in Figure (22). From the obtained data, the increasing adsorbent amount from 20 to $150 \mathrm{mg}$ the $\mathrm{Pb}^{2+}, \mathrm{Ni}^{2+}$, and $\mathrm{Zn}^{2+}$ ions removal are gradually increased. This tendency was as expected because of the fact that the increasing amount of AIAB provided more adsorption sites to adsorb all the studied metal ions, whereas a decreased the uptake amounts $\left(\mathrm{q}_{\mathrm{e}}\right)$ are also observed, which can be explained by the solid effect. Posteriorly, the removal efficiencies of the metal ions are constant at the adsorbent amount 150-250 $\mathrm{mg}$. Therefore, the amount of adsorbent is selected as $150 \mathrm{mg}$ for further adsorption experiments. 


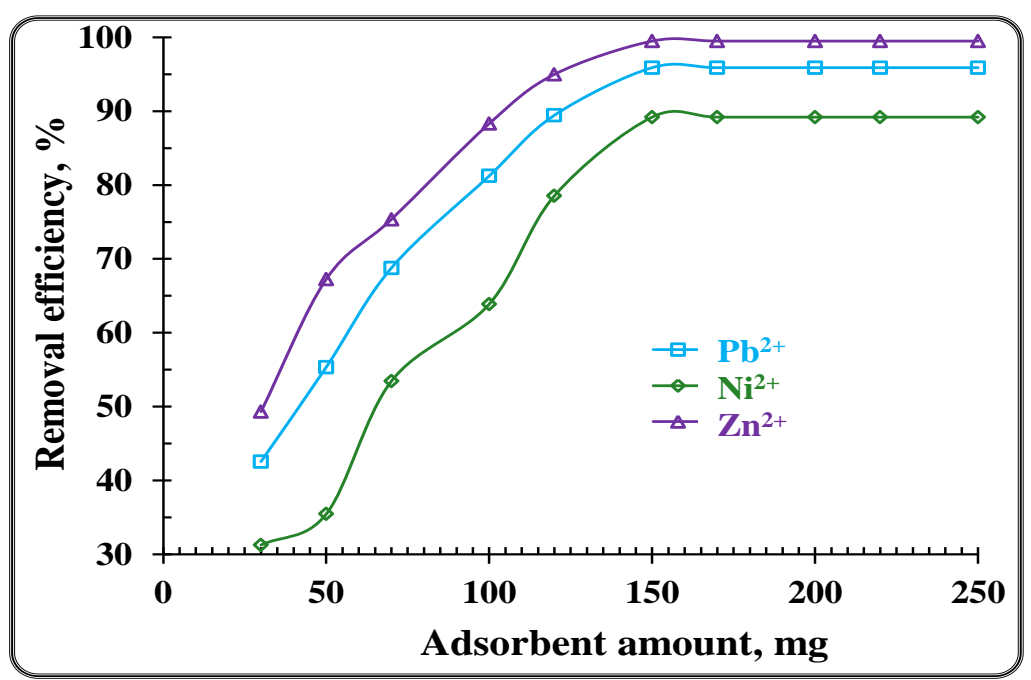

Figure 22: Effect of the adsorbent amount on the removal of the $\mathrm{Pb}^{2+}, \mathrm{Ni}^{2+}$, and $\mathrm{Zn}^{2+}$ from WPPA.

\subsubsection{Effect of acid volume}

The effect of the acid volume is studied by increasing the volume of WPPA from 20 to $200 \mathrm{ml}$ while fixing the weight of adsorbent at $150 \mathrm{mg}$ at room temperature for $60 \mathrm{~min}$ stirring time. From the results shown in Figure (23), it is inferred that the maximum removal efficiencies are constant until $50 \mathrm{ml}$ acid volume, by increasing the acid volume more than 50 $\mathrm{ml}$, the removal efficiencies are decreased. It can be seen that the studied metal impurities uptake are clearly constant in the first until $50 \mathrm{ml}$ acid volume due to the presence more adsorbent active sites on the AIAB surface, after $50 \mathrm{ml}$ acid volume, the AIAB active sites are completely blocked with the required enough of the $\mathrm{Pb}^{2+}, \mathrm{Ni}^{2+}$, and $\mathrm{Zn}^{2+}$ ions. Consequently, the initial amount of metal impurities are increased in solution by acid volume increased, therefore the removal efficiencies are decreased. Therefore, the acid volume of $50 \mathrm{ml}$ was found to be appropriate for maximum removal of the studied metal ions on AIAB.

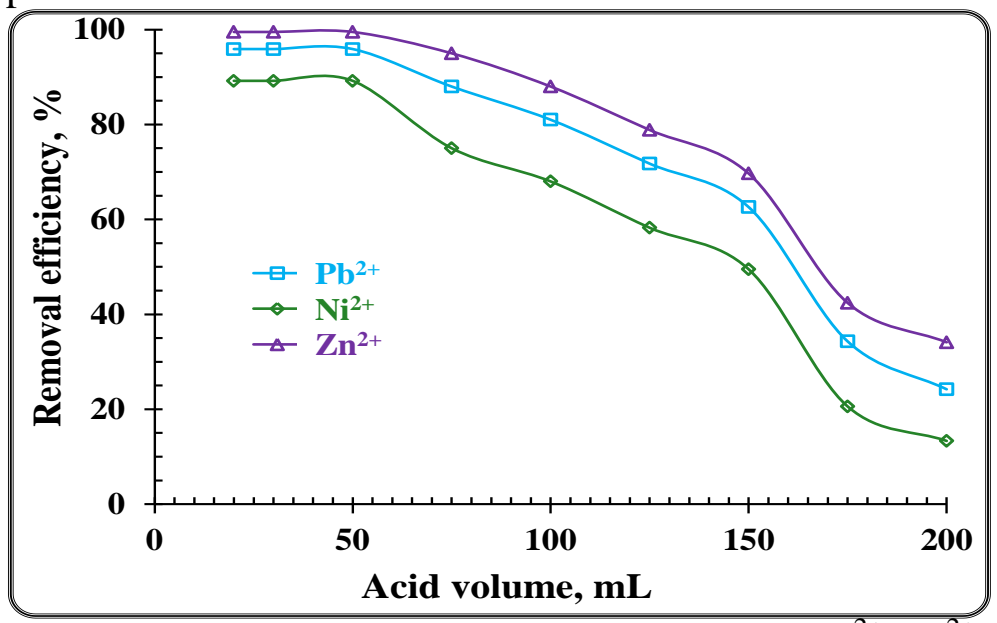

Figure 23: Effect of acid volume of WPPA on the removal of the $\mathrm{Pb}^{2+}, \mathrm{Ni}^{2+}$, and $\mathrm{Zn}^{2+}$, ions by AIAB adsorbent.

\subsubsection{Effect of temperature}

The removal of the $\mathrm{Pb}^{2+}, \mathrm{Ni}^{2+}$, and $\mathrm{Zn}^{2+}$ ions from WPPA at different temperatures $\left(25-55{ }^{\circ} \mathrm{C}\right)$ are studied under the fixed conditions of $50 \mathrm{ml}$ of WPPA, 
$150 \mathrm{mg}$ AIAB for $60 \mathrm{~min}$ stirring time. The results are represented in Figure (24), it is exhibited that the removal efficiencies of the $\mathrm{Pb}^{2+}, \mathrm{Ni}^{2+}$, and $\mathrm{Zn}^{2+}$ ions from WPPA are decreased with increase in temperature. This is due to the failing of the strength of the binding and attraction between metal ions and active site on the surface of AIAB adsorbent. Hence, the maximum removal efficiencies are obtained at room temperature.

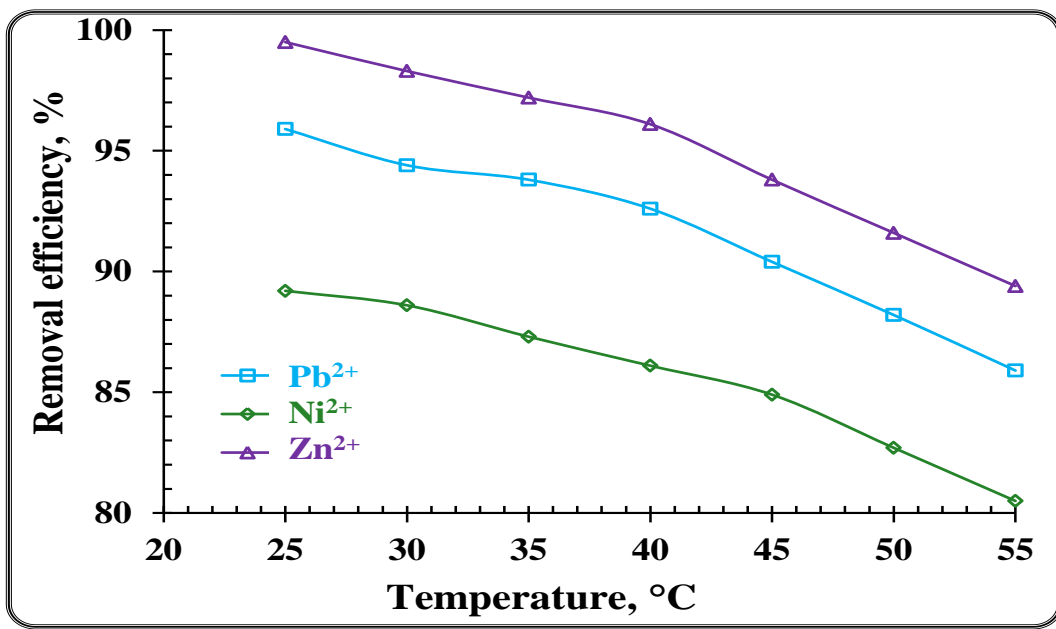

Figure 24: Effect of temperature on the removal of the $\mathrm{Pb}^{2+}, \mathrm{Ni}^{2+}$, and $\mathrm{Zn}^{2+}$ ions from WPPA by AIAB adsorbent.

\subsection{Characterization of the purified Abu Zaabal wet process phosphoric acid}

According to the previous investigation, $15 \mathrm{~g}$ Alizarin impregnated activated bentonite (AIAB), as an adsorbent is contacted and stirred with $5 \mathrm{~L}$ of WPPA in a mechanical shaker (200 rpm) for 60 min equilibrium time at room temperature. The filtration process is applied and the acquired purified WPPA is completely analyzed by ICP-OES. From the data in Table (4), majority of metal impurities are reduced to obtain the pure wet process phosphoric acid. In the other hand, the adsorbent loaded with the inorganic impurities is reused and regenerated by the chosen eluent solution $\left(100 \mathrm{ml}\right.$ of $\left.1 \mathrm{M} \mathrm{H}_{2} \mathrm{SO}_{4}\right)$ under fixed conditions of $60 \mathrm{~min}$ contact time at room temperature.

Table (4): Analysis of Abu Zaabal WPPA and it's purified with AIAB adsorbent.

\begin{tabular}{|c|c|c|c|c|c|}
\hline Constituents & $\begin{array}{c}\text { WPPA, } \\
(\%)\end{array}$ & $\begin{array}{c}\text { Purified } \\
\text { WPPA } \\
(\%)\end{array}$ & Constituents & $\begin{array}{c}\text { WPPA, } \\
\text { mg/L }\end{array}$ & $\begin{array}{c}\text { Purified } \\
\text { WPPA } \\
(\mathrm{mg} / \mathrm{L})\end{array}$ \\
\hline $\mathrm{P}_{2} \mathrm{O}_{5}$ & 29.00 & 29.00 & $\mathbf{U}^{6+}$ & 36.0 & 6.0 \\
\hline $\mathrm{CaO}$ & 0.46 & 0.36 & $\mathbf{P b}^{2+}$ & 30.0 & 2.0 \\
\hline $\mathbf{F}^{-}$ & 0.53 & 0.32 & $\mathrm{Ni}^{2+}$ & 42.0 & 4.0 \\
\hline $\mathrm{SiO}_{2}$ & 0.33 & 0.23 & $\mathrm{Cd}^{2+}$ & 12.0 & 1.0 \\
\hline $\mathrm{Na}_{2} \mathrm{O}$ & 0.20 & 0.08 & $\mathrm{Zn}^{2+}$ & 188.0 & 12.0 \\
\hline $\mathbf{K}_{2} \mathbf{O}$ & 0.06 & 0.02 & $\mathrm{Cu}^{2+}$ & 28.0 & 3.0 \\
\hline MgO & 0.33 & 0.03 & $\mathrm{Mn}^{2+}$ & 453.0 & 53.0 \\
\hline $\mathrm{Fe}_{2} \mathrm{O}_{3}$ & 1.60 & 0.65 & $\mathrm{As}^{5+}$ & 4.0 & 1.0 \\
\hline $\mathrm{Cl}^{-}$ & 1.80 & 0.83 & $\mathrm{Cr}^{3+}$ & 140.0 & 40.0 \\
\hline $\mathrm{Al}_{2} \mathrm{O}_{3}$ & 0.40 & 0.09 & $\mathrm{Co}^{3+}$ & 28.0 & 12.0 \\
\hline $\mathrm{SO}_{4}{ }^{2-}$ & 1.20 & 0.65 & $\mathbf{R E}^{3+}$ & 170.0 & 17.0 \\
\hline
\end{tabular}




\section{Conclusion}

The removal of the $\mathrm{Pb}^{2+}, \mathrm{Ni}^{2+}$, and $\mathrm{Zn}^{2+}$ ions from the wet process phosphoric acid are fulfilled by Alizarin modified bentonite which characterized by XRD, SEM-EDX, and FT-IR techniques. The obtained optimized adsorption conditions of the batch technique are attained using $50 \mathrm{ml}$ of $5 \mathrm{M}$ synthetic solution of phosphoric acid. These parameters are $50 \mathrm{ml}$ of $5 \mathrm{M}$ $\mathrm{H}_{3} \mathrm{PO}_{4}, 50 \mathrm{mg}$ AIAB, 60 min contact time, room temperature. Under these conditions, the realized maximum uptake capacities of $\mathrm{Pb}^{2+}, \mathrm{Ni}^{2+}$, and $\mathrm{Zn}^{2+}$ ions on $\mathrm{AIAB}$ adsorbent attained $121.5,82.5$, and $141.7 \mathrm{mg} / \mathrm{g}$ at room temperature respectively. The adsorption-desorption procedures are repeated the number of times up to desorption efficiencies are reduced from $98 \%$ to $82 \%$ for the studied adsorbent after five consecutive cycles, which indicated that the good adsorption stability of the AIAB adsorbent for $\mathrm{Pb}^{2+}, \mathrm{Ni}^{2+}$, and $\mathrm{Zn}^{2+}$ ions. In the other hand, the obtained results have finally been applied on the WPPA to removal the studied metal impurities. The results achieve with good removal and highly purified WPPA.

\section{References}

Aaltonen J., Riihimäki S., Ylinen P., Weckman A., Process for production of phosphoric acid by crystallization of phosphoric acid hemihydrates. Justia Patents, Patent number: 6814949, 2004.

Abdel Aal E.A., Amer A.M., Evaluation of Sebaiya west phosphate concentrate for nitrophosphate fertilizer production. Bull. Faculty of Science, Alexandria University 31(B), 1991, 344-359.

Abdennebi N., Bagane M., Chtara C., Removal of copper from phosphoric acid by adsorption on Tunisian bentonite. Chemical Engineering \& Process Technology 4(6), 2013, 1-4.

Abdennebi N., Benhabib K., Goutaudier C., Bagane M., Removal of aluminium and iron ions from phosphoric acid by precipitation of organo-metallic complex using organophosphorous reagent. Journal of materials and Environmental Sciences 8(2), 2017, 557-565.

Abdou M.I., Al-sabagh A.M., Dardir M.M., Evaluation of Egyptian bentonite and nanobentonite as drilling mud. Egyptian Journal of Petroleum 22, 2013, 53-59.

Alexandre B., Langevin D., Médéric P., Aubry T., Couderc H., Nguyen Q.T., Saiter A., Marais S., Water barrier properties of polyamide 12/montmorillonite nanocomposite membranes: Structure and volume fraction effects. Journal of Membrane Science 328, 2009, 186-204.

Al-Harahsheh M., Hussain Y.A., Al-Zoubi H., Batiha M., Hammouri E., Hybrid precipitationnanofiltration treatment of effluent pond water from phosphoric acid industry. Desalination 406, 2017, 88-97.

Assuncao M.C., Cote G., Andre M., Halleux H., Chagnes A., Phosphoric acid recovery from concentrated aqueous feeds by a mixture of di-isopropyl ether (DiPE) and tri-nbutylphosphate (TBP): extraction data and modeling. Royal Sociaty of Chemistry Advances 7, 2017, 6922-6930. 
Awwad N.S., El-Nadi Y.A., Hamed M.M., Successive processes for purification and extraction of phosphoric acid produced by wet process. Arab Journal of Nuclear Science and Applications 46(1), 2013, 67-77.

Becker, P., Phosphates and Phosphoric Acid: Raw materials- Technology, and Economics of the Wet-Process. 2nd edition, Marcel Dekker Inc., New York, 1989.

Bihannic I., Tchoubar D., Lyonnard S., Besson G., Thomas F., X-Ray scattering investigation of swelling clay fabric: 1 . The dry state. Journal of Colloid and Interface Science 240(1), 2001, 211-218.

Cheira M.F., Characteristics of uranium recovery from phosphoric acid by an aminophosphonic resin and application to wet process phosphoric acid. European Journal of Chemistry 6(1), 2015, 48-56.

Cheira M.F., Zidan I.H., Manaa E.A., Potentiality of white sand for the purification of wet process phosphoric acid from some metallic elements (U, Zn, Cd). Chemical Technology An Indian Journal 9(6), 2014, 224-233.

Chen A., Zhu J., Wu B., Chen K., Ji L., Continuous melt suspension crystallization of phosphoric acid. Journal of Crystallization Process and Technology 2, 2012, 111-116.

Chen H., Sun Z., Song X., Yu J., Efficient extraction of phosphoric acid with a trialkyl aminebased solvent mixture. Journal of Chemical Engineering \& Data 61(1), 2016, 438-443.

Christidis G. E., Scott P. W., Dunham A. C., Acid activation and bleaching capacity of bentonites from the islands of Milos and Chios, Aegean and Greece. Appl. Clay Sci. 12, 1997, 329-347.

Duan X., Evans D.G., Layered Double Hydroxides. Vol. 119, Springer Verlag, Berlin, Heidelberg, 2006, pp. 89-119.

Elleuch M.B.C., Amor M.B., Pourcelly G., Phosphoric acid purification by a membrane process: Electrodeionization on ion-exchange textiles. Separation and Purification Technology 51(3), 2006, 285-290.

El-Sofany E.A, Zaher W.F., Aly H.F., Sorption potential of impregnated charcoal for removal of heavy metals from phosphoric acid. Journal of Hazardous Materials 165, 2009, 623629.

El-Zahhar A.A., El-Naggar H.A., Ahmed A.M., Polymeric supported sorbents for decreasing hazardous metal ions content in wet process phosphoric acid. 8th Arab International Conference on Polymer Science \& Technology, 27 - 30 November 2005, Cairo, Sharm El-Shiekh, Egypt, 2005.

Foods Standards Agency, Food.gov.uk, EU Approved additives and E Numbers, Food additives legislation guidance to compliance. October 2015.

Forano C., Hibino T., Leroux F., Taviot-Gueho C., Layered double hydroxides, in: Bergaya F., Theng B.K.G., Lagaly G. (Eds.), Handbook of Clay Science. Elsevier, Amsterdam, 2006, pp. 1021-1096.

Grim R.E., Clay Mineralogy. 2nd edition, McGraw-Hill Book Company, New York, 1968, 41.

Haraldsen H.F.T., Method for removal of heavy metals, especially cadmium, from phosphoric acid containing solutions. United States Patent, P. Number 4986970, 1991.

Kabay N., Gizli N., Demircioðlu M., Arda M., Yüksel Ü., Removal of cadmium from phosphoric acid solution by solvent-impregnated resins. In : Camarda D. (ed.), Grassini L. (ed.), Coastal zone management in the Mediterranean region. Options Méditerranéennes: Série A. Séminaires Méditerranéens; n. 53, Bari: CIHEAM 53, 2002, $71-76$. 
Khoualdia B., Loungou M., Elaloui E., Adsorption of organic matter from industrial phosphoric acid (H3PO4) onto activated bentonite. Arabian Journal of Chemistry 10(1), 2017, S1073-S1080.

Kussainova M.Z., Chernyakova R.M., Jussipbekov U.Z., Pasa S., Temel H., Removal of $\mathrm{Pb} 2+, \mathrm{Cd} 2+$, and $\mathrm{Cu} 2+$ from phosphoric acid solution using the chitosan-modified natural zeolite. Asia-Pacfic Journal of Chemical Engeering 10(6), 2015, 833-841.

Li X., Li J., Luo J., Jin Y., Zou D., Purification of Wet process phosphoric acid by solvent extraction using cyclohexanol. Solvent Extraction Research and Development, Japan 24(1), 2017, 23-35.

Lokshin E., Vershkova Y., Vershkov A., Tareeva O., Leaching of lanthanides from phosphohemihydrate with nitric acid. Russian Journal of Applied Chemistry 75(11), 2002, 1753-1759.

Machorro J.J., Olvera J.C., Larios A., Hernández-Hernández H.M., Alcantara-Garduño M.E., Orozco G., Electrodialysis of Phosphates in Industrial-Grade Phosphoric Acid. Electrochemistry 2013, 2013, 1-12.

Marcus Y., Gupta A.K., Marinsky J.A., Ion Exchange and Solvent Extraction, A Series of Advances. Marcel Dekker, Inc., New York, Vol. 14, 390 p (2004).

Monser L., Amor M.B., Ksibi M., Purification of wet phosphoric acid using modified activated carbon. Chemical Engineering and Processing 38(3), 1999, 267-271.

Odom I.E., Smectite clay minerals: properties and uses. Phil. Trans. R. Soc. Lond. A 311, 1984, 391-409.

Reyes L.H., Medina I.S., Mendoza R.N., Vázquez J.R., Rodríguez M.A., Guibal E., Extraction of cadmium from phosphoric acid using resins impregnated with organophosphorus extractants. Industrial \& Engineering Chemistry Research 40 (5), 2001, 1422-1433.

Saleh A.S., El-Zahhar A.A., Adsorption of iron(III) from phosphoric acid solution on aminotrimethylene phosphonic acid impregnated resin. Arab Journal of Nuclear Science and Applications 48(4), 2015, 1-12.

Shapiro L., Brannock W.W., Rapid analysis of silicate, carbonate and phosphate rocks. U.S. Geol. Surv. Bull. 1144. A, 1962, 56.

Singh S.K., Dhami P.S., Tripathi S.C., Dakshinamoorthy A., Studies on the recovery of uranium from phosphoric acid medium using synergistic mixture of (2-Ethyl hexyl) Phosphonic acid, mono (2-ethyl hexyl) ester (PC88A) and Tri-n-butyl phosphate (TBP). Hydrometallurgy 95, 2009, 170-174.

Slack A.V., Phosphoric Acid. Volume I, Part 1 and 2, Published by Marcel Dekker, Inc., New York, 1968.

Sultanbayeva G.S., Holze R., Chernyakova R.M., Jussipbekov U.Z., (): Removal of Fe2+, $\mathrm{Cu} 2+, \mathrm{Al} 3+$ and $\mathrm{Pb} 2+$ ions from phosphoric acid by sorption on carbonate-modified natural zeolite and its mixture with bentonite. Microporous and Mesoporous Materials 170, 2013, 173-180.

Taha M.H., El-Maadawy M.M., Hussein A.E.M., Youssef W.M., Uranium sorption from commercial phosphoric acid using kaolinite and metakaolinite. Journal of Radioanalytical and Nuclear Chemistry 317, 2018, 685-699.

Vimonses V., Lei S., Jin B., Chow C.W.K., Saint C., Kinetic study and equilibrium isotherm analysis of congo red adsorption by clay materials. Chem. Eng. J. 148, 2009, 354-364.

Wang G., Wang X., Chai X., Liu J., Deng N., Adsorption of uranium (VI) from aqueous solution on calcined and acid-activated kaolin. Applied Clay Science 47, 2010, 448451. 


\section{الملخص باللغة العربية}

إستخدام البنتونيت المعدل بالأيزارين لإزالة بعض أيونات المعادن الثقيلة من حمض الفوسفوريك

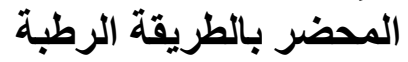

محمد أحمد عوض اللهّ1 ، محـمد نجيب راشــ 1، عديلة السعدي محـمد، محمد فريد شعيرة 2

$$
\begin{aligned}
& \text { | اـقسم الكيمياء - كلية العلوم -جامعة أسوان - مصر }
\end{aligned}
$$

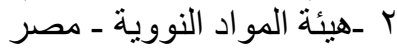

يهذف البحث إلي إز الة أيونات الرصاص و النيكل و الزنك من حمض الفوسفوريك

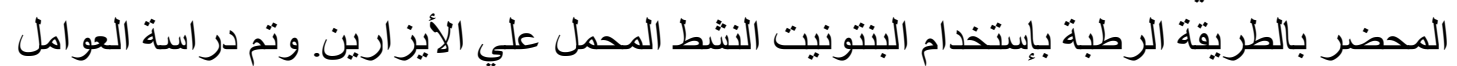

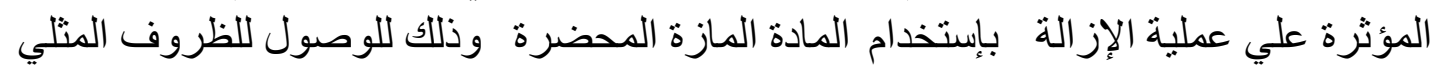

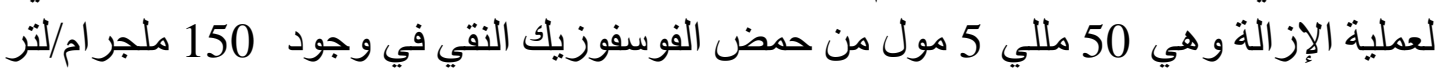

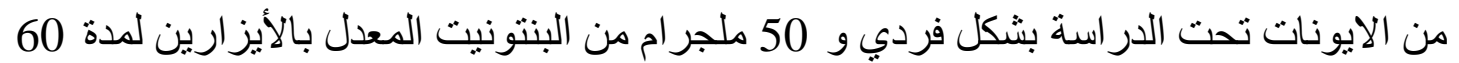

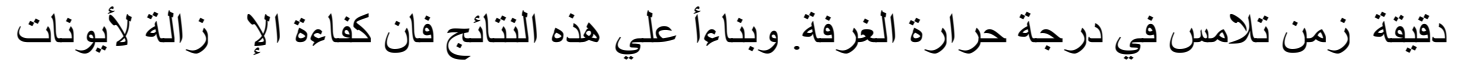

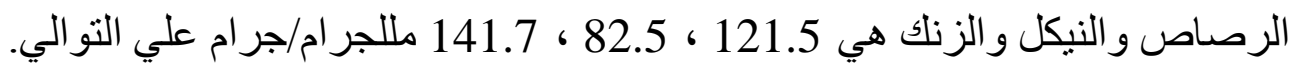

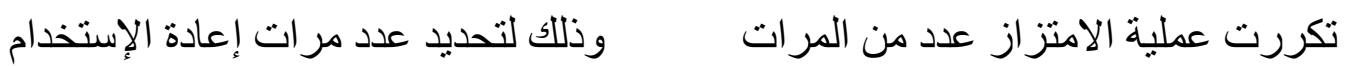

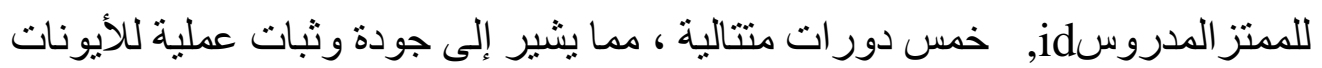

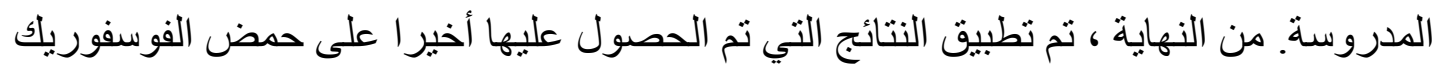

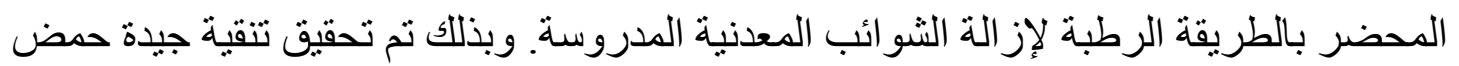
الفوسفوريك المحضر بالطريقة الرطبة. 